\title{
Cell death and diseases related to oxidative stress: 4-hydroxynonenal (HNE) in the balance
}

\author{
S Dalleau ${ }^{1,2}, M_{\text {Baradat }}{ }^{1,2}, F_{\text {Guéraud }}{ }^{1,2}$ and L Huc ${ }^{\star, 1,2}$
}

During the last three decades, 4-hydroxy-2-nonenal (HNE), a major $\alpha, \beta$-unsaturated aldehyde product of $n-6$ fatty acid oxidation, has been shown to be involved in a great number of pathologies such as metabolic diseases, neurodegenerative diseases and cancers. These multiple pathologies can be explained by the fact that HNE is a potent modulator of numerous cell processes such as oxidative stress signaling, cell proliferation, transformation or cell death. The main objective of this review is to focus on the different aspects of HNE-induced cell death, with a particular emphasis on apoptosis. HNE is a special apoptotic inducer because of its abilities to form protein adducts and to propagate oxidative stress. It can stimulate intrinsic and extrinsic apoptotic pathways and interact with typical actors such as tumor protein 53, JNK, Fas or mitochondrial regulators. At the same time, due to its oxidant status, it can also induce some cellular defense mechanisms against oxidative stress, thus being involved in its own detoxification. These processes in turn limit the apoptotic potential of HNE. These dualities can imbalance cell fate, either toward cell death or toward survival, depending on the cell type, the metabolic state and the ability to detoxify.

Cell Death and Differentiation (2013) 20, 1615-1630; doi:10.1038/cdd.2013.138; published online 4 October 2013

\section{Bullet Points}

- 4-hydroxy-2-nonenal (HNE), a secondary product of lipoperoxidation, can form protein adducts and modifies cell signaling.

- Because of its chemical reactivity, HNE can exert pleiotropic effects particularly in cell death.

- HNE is accumulated in numerous oxidative stress-related diseases, such as neurodegenerative diseases (NDD), cardiovascular diseases, metabolic syndrome and cancer.

- The regulation of cell death by HNE can impact the development of diseases associated with oxidative damage.

\section{Open Questions}

- What are the mechanisms of cell death induced by HNE?

- What is the relative importance of the canonical apoptotic pathways compared with atypical cell deaths in HNE-exposed cells?
- Upon HNE exposure, what are the processes to avoid death?

- How do the detoxification pathways modulate the cell fate upon HNE exposure?

\section{4-Hydroxynonenal: a Highly Reactive Product of Lipoperoxidation}

Non-enzymatic lipoperoxidation (LPO) is an autocatalytic process, initiated by the attack of free radicals on membrane polyunsaturated fatty acids (PUFAs). The $\alpha, \beta$-unsaturated aldehyde 4-hydroxynonenal (HNE) is a major end product that is derived from the oxidation of $n-6$ PUFAs such as linoleic, $\gamma$-linolenic or arachidonic acids. HNE belongs to the advanced lipid peroxidation end products (ALEs). Despite its relative stability compared with free radicals, the chemical structure of HNE possesses three reactive functions: a $\mathrm{C} 2=\mathrm{C} 3$ double bond, a $\mathrm{C} 1=\mathrm{O}$ carbonyl group and a hydroxyl group on

\footnotetext{
${ }^{1}$ INRA, TOXALIM (Research Centre in Food Toxicology), 180 chemin de Tournefeuille, F-31027 Toulouse, France and ${ }^{2}$ Université de Toulouse III, INP, ENVT, UPS, TOXALIM, F-31027 Toulouse, France

*Corresponding author: L Huc, INRA, TOXALIM (Research Centre in Food Toxicology), 180 chemin de Tournefeuille. F-31027 Toulouse, France. Tel: +33 561285014; Fax: +33 561285244; E-mail: Laurence.Huc@toulouse.inra.fr

Keywords: lipoperoxidation; apoptosis; detoxification; protein adduct; oxidative stress

Abbreviations: AIF, apoptosis-inducing factor; AKR, aldo-keto reductase; ALDH, aldehyde dehydrogenase; ALE, advanced lipid peroxidation end product; AP-1, activator protein 1; ASK1, apoptosis signal-regulating kinase 1; Bcl2, B-cell lymphoma 2; Cdc, cell division cycle homolog; CDK, cyclin-dependent kinase; cyt.c, cytochrome c; Daxx, death domain-associated protein; DHN, 1,4-dihydroxy-2-nonene; DISC, death-inducing signaling complex; ER, endoplasmic reticulum; FADD, Fas-associated protein with death domain; FasL, Fas ligand; GSH, glutathione; GST, gluthatione S-transferase; HNA, 4-hydroxynonenoïc acid; HNE, 4-hydroxy-2nonenal; HO-1, heme oxygenase 1; HSF, heat shock factor; Hsp, heat shock protein; hTERT, human telomerase reverse transcriptase; I $\mathrm{B}$, inhibitor of kappa B; IKK, $I_{\kappa}$ B kinase; JNK, c-Jun N-terminal kinase; Keap-1, Kelch-like ECH-associated protein 1; LDL, low-density lipoprotein; LMP, Iysosomal membrane permeabilization; LPO, lipoperoxidation; MCP-1, monocyte chemotactic protein 1; MOMP, mitochondrial outer membrane permeabilization; MRP, multidrug-resistant protein; NAFLD, non-alcoholic fatty liver disease; NDD, neurodegenerative diseases; NF $\kappa B$, nuclear factor-kappa B; NQO1, NAD(P)H dehydrogenase (quinone) 1; Nrf2, Nuclear factor (erythroid-derived 2)-like 2; p53, tumor protein 53; PDGFR, platelet-derived growth factor receptor; PUFA, polyunsaturated fatty acid; Rb, retinoblastoma protein; RLIP76, RalA-binding protein 16 encoded 76-kDa splice variant; ROS, reactive oxygen species; TGF $\beta$, transforming growth factor $\beta$; Trx1, thioredoxin reductase 1; TNF, tumor necrosis factor; TRAIL, TNF-related apoptosis-inducing ligand; UPR, unfolded protein response; VSMC, vascular smooth muscle cells; XIAP, X-linked inhibitor of apoptosis protein

Received 03.4.13; revised 22.7.13; accepted 29.7.13; Edited by RA Knight; published online 04.10.13
} 
C4 (Figure 1). These reactive functions make this electrophilic molecule highly reactive toward nucleophilic thiol and amino groups. This reactivity relies upon both the Michael addition of thiol or amino compounds on the $\mathrm{C} 3$ of the $\mathrm{C} 2=\mathrm{C} 3$ double bond and the formation of Schiff bases between the $\mathrm{C} 1$ carbonyl group and primary amines. The kinetics of the Schiff base formation are inherently slow and reversible, making Michael-adducts predominant. HNE can then react with a large number of macromolecules such as proteins, principally those containing histidine, cysteine and lysine residues; lipids, which contains an amino group; and with nucleic acids, mostly with the guanosine moiety of DNA. ${ }^{1}$ These interactions with proteins, called HNE-protein adduction, modify their activity (for a review, see Schaur et al. ${ }^{1}$ ). Because of its double reactivity (Michael addition and Schiff bases), HNE can contribute to protein cross-linking and induce a carbonyl stress.

Under physiological conditions, cells have to cope with HNE stemming from different sources. The most common source is the endogenous one, coming from the reactive oxygen species (ROS) produced by the mitochondrial electron transport chain, which triggers lipid oxidation. When the cells are exposed to xenobiotics, the cytochrome P450 biotransformation activities can also generate ROS that are able to induce LPO. Thus, HNE generation has been associated with drugs or exposure to environmental contaminants, such as ethanol. $^{2}$ Inflammation-related ROS are also a prominent source of HNE, and HNE-protein adducts are biomarkers in inflammatory diseases. ${ }^{3}$ Exogenous HNE is another way for the cells to be exposed. It can be produced by peroxidation of plasma low-density lipoproteins (LDL) ${ }^{4}$ or generated during food processing: the heme iron present in red meat can oxidize dietary polyunsaturated lipids. ${ }^{5}$ Intestinal cells are also major targets of exogenous HNE because they are at the interface with the lumen and can be directly exposed to high concentrations of HNE. Moreover, HNE can be produced by macrophages infected by gut microbiota and such generated HNE can be toxic for colon cells. ${ }^{6}$ As HNE is a highly diffusible molecule, it can spread beyond its initial production site. Based upon its diffusion capacity, it has been suggested that HNE can act as a paracrine signal molecule. ${ }^{7}$

Because of the basal level of ROS inherent to life under aerobic conditions, there should be a basal level of HNE in the cell. The HNE concentration in human blood and serum was estimated to be about $0.05-0.15 \mu \mathrm{M},{ }^{8,9}$ but in pathological situations and close to the core of LPO sites, its concentration can be greatly increased (more than $100 \mu \mathrm{M}$ ). ${ }^{10}$ Thus, high levels of HNE have been detected in a large number of diseases. ${ }^{11,12}$ Nevertheless, even if HNE can be detected by several methods, acquiring reliable values of HNE in vivo is considerably compromised by its rapid metabolism, its efflux and its steady-state concentration in specific tissues. ${ }^{13}$ All cells are not equal regarding HNE detoxification. As an example, colonocytes metabolize $100 \%$ of $40 \mu \mathrm{M}$ HNE in $90 \mathrm{~min},{ }^{14}$ whereas hepatocytes metabolize $95 \%$ of $100 \mu \mathrm{M}$ HNE in 3 min. ${ }^{15}$ Therefore, the concentration of HNE and the duration of exposure can be modulated by the rate of detoxification in target organs.

Depending on its concentration and its targets, HNE can contribute to many biological functions: for example, stimulating or inhibiting enzymatic functions, such as kinases (PKC (protein kinase C). ${ }^{16}$ HNE interaction with key amino acids of catalytic sites could explain the inhibition of these enzymes. ${ }^{16}$ Although HNE-dependent protein modulation relies mainly on post-translational modifications, the regulation of gene expression by HNE has also been described notably by modulation of NF- $\kappa \mathrm{B}$ (nuclear factor-kappa B) and AP-1 (activator protein 1) transcription factors, which are related to

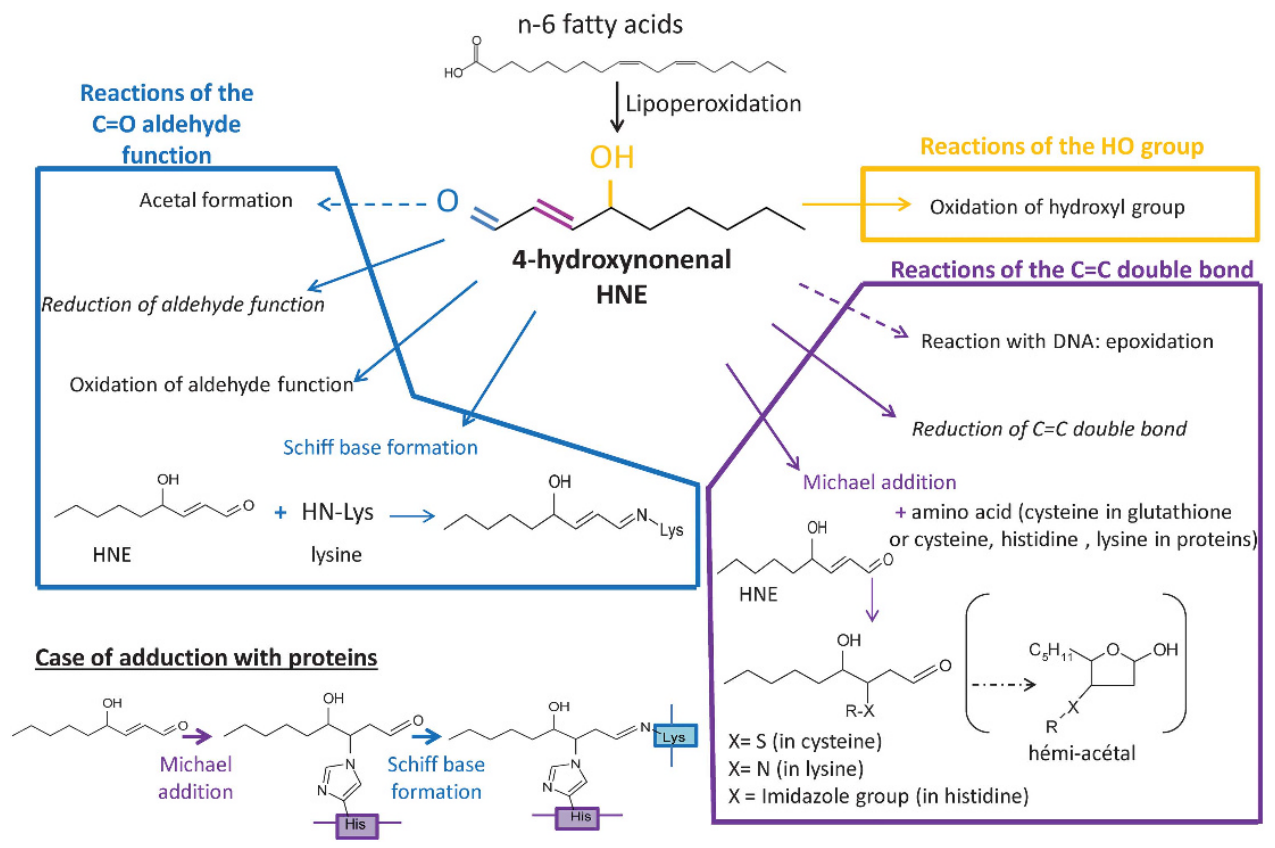

Figure 1 Reactivity of HNE. Here are represented the potential reactions of HNE on the hydroxyl, carbonyl and double bond groups. HNE is biotransformed, but it can also react with proteins according to the Michael addition and the Schiff base formation and DNA by epoxidation 
Table 1 Involvement of $\mathrm{HNE}$ in diseases related to oxidative stress

\begin{tabular}{|c|c|c|}
\hline Pathologies & In vivo and in vitro data & References \\
\hline \multirow[t]{3}{*}{ Alzheimer's disease } & HNE-modified proteins $\nearrow$, proteasome activity $\searrow$, inflammation $\nearrow$, neurodegeneration $\nearrow$ & 28,29 \\
\hline & HNE-synaptosomal proteins conjugation, glucose transport $\searrow$, mitochondrial ROS $\nearrow$, synaptic degeneration $\nearrow$ & 30 \\
\hline & HNE-induced ion homeostasis disturbance, $\mathrm{Na}^{+} / \mathrm{K}^{+}$ATPase activity $\searrow$, free $\mathrm{Ca}^{2+} \nearrow$, cell degeneration $\nearrow$ & 31 \\
\hline \multirow[t]{3}{*}{ Parkinson's disease } & HNE-modified proteins $\nearrow$, proteasome activity $\searrow$, free radical generation $\nearrow$, oxidative stress $\nearrow$, dopaminergic cell death $\nearrow$ & 32 \\
\hline & HNE-modified proteins $\nearrow$, proteasome activity $\searrow$, free radical generation $\nearrow$, & 33 \\
\hline & Dopamine uptake $\searrow, \mathrm{Na}^{+} / \mathrm{K}^{+}$ATPase activity $\searrow$ & 35 \\
\hline \multirow[t]{4}{*}{ Cancer } & HNE-guanosine adducts, G C to T.A mutations on p53 $\nearrow$, DNA repair mechanisms $\searrow$ & $60-62$ \\
\hline & Low levels of HNE in tumor tissues compared with healthy tissues, $\searrow$ TGF $\beta 1$ & $46-48,49$ \\
\hline & High levels of HNE in cancer tissues & $50-55$ \\
\hline & Luminal HNE triggers the positive selection of preneoplastic cells in colorectal cancer & 14,59 \\
\hline \multirow[t]{2}{*}{ Atherosclerosis } & HNE-induced oxidative stress, IL-8 $\searrow$, ICAM- $1 \searrow$, cytotoxicity $\nearrow$, endothelial barrier abilities $\searrow$, apoptosis $\nearrow$ & 40 \\
\hline & HNE-induced class A scavenger receptor synthesis, macrophage foam cells formation $\nearrow$, lipid cores formation $\nearrow$ & 37,38 \\
\hline \multirow[t]{2}{*}{ Liver diseases } & HNE-induced JNK pathway, hepatocytes cell death $\nearrow$ (NAFLD) & 43 \\
\hline & HNE modification of 'self'-proteins, autoimmune reactions $>$ (ALD) & 2,44 \\
\hline
\end{tabular}

HNE, 4-hydroxy-2-nonenal; JNK, c-Jun N-terminal kinase; NAFLD, non-alcoholic fatty liver disease; ROS, reactive oxygen species; TGF $\beta 1$, transforming growth factor $\beta$ Special character for 'arrow going up': increase; special character for 'arrow going down': decrease.

stress responses. It is particularly involved in the activation of the transcription factor Nrf2 (nuclear factor (erythroidderived 2)-like 2), which transactivates the antioxidant responsive element (ARE). By doing so, it stimulates the cellular antioxidant defenses and the regulation of the oxidative stress, via the upregulation of the expression of various genes such as for heme oxygenase 1 (HO-1), aldehyde dehydrogenases (ALDH), glutathione S-transferase (GST), multidrug-resistant proteins (MRPs), aldose reductase (aldo-keto reductase, AKR), NADPH dehydrogenase quinone 1 (NQO1) or glutamate-cysteine ligase (GCL). ${ }^{17}$ Some of these genes were shown to be involved in HNE biotransformation. ${ }^{18}$ The physiological levels of HNE also have to be taken into account, as the depletion of HNE can affect gene expression such as Fas, Tp53, p21, c-myc or connexin 43. ${ }^{19}$

By its multiple impacts on protein regulation through transcriptional and post-translational modifications, HNE has a role in the maintenance of cellular homeostasis, during normal aerobic metabolism (low levels of ROS). However, higher and longer oxidative stress can lead to HNE accumulation thereby compromising cellular functions, as is the case in some pathological disorders. ${ }^{20}$

\section{HNE and Diseases Associated with Oxidative Damage: Links to Cell Death}

High levels of HNE have been associated with diseases involving redox imbalance: NDD, ${ }^{21}$ macular degeneration, ${ }^{22}$ cardiovascular diseases, atherosclerosis, ${ }^{23}$ metabolic syndrome $^{24}$ and cancers. ${ }^{25}$ In these diseases, HNE is not only a simple marker of oxidative stress but also a causative agent. The modalities of HNE involvement in these oxidative stress-related diseases are detailed below and summarized in the Table 1.

Neurodegenerative diseases. In Alzheimer's disease, where increased oxidative damage in neuronal cell bodies is one of the earliest changes, HNE-adducts to neurofilaments have been found. ${ }^{26}$ It is the amyloid $\beta$-peptide that would induce oxidative stress and the consequent lipoperoxidation. High levels of HNE have been detected in amyloid $\beta$ plaques and in the cerebrospinal fluid in Alzheimer's patients. ${ }^{27}$ The accumulation of HNE-modified amyloid $\beta$-peptides has been shown to inhibit the proteasome, ${ }^{28}$ and the resulting accumulation of ubiquitinated modified proteins leads to a proinflammatory response (cyclo-oxygenase 2, prostaglandins). This contributes to neurodegeneration. ${ }^{29}$ Moreover, by modifying membranes, HNE could impair $\mathrm{Na}^{+} / \mathrm{Ca}^{2+}$ pumps and glucose and glutamate transporters, leading to ionic and energetic disturbances and neuronal cell death. ${ }^{30,31}$

In Parkinson's disease, oxidative stress is known to contribute to mitochondrial dysfunction and degeneration of dopaminergic cells. ${ }^{21}$ HNE can form adducts with proteins involved in the proteasome system, leading to its failure and neuronal cell death. ${ }^{32}$ HNE has been shown to be present in the mitochondria and Lewy bodies. In vitro experiments have revealed that the incubation of dopaminergic neurons with HNE leads to a decrease in dopamine uptake and a loss of $\mathrm{Na}^{+} / \mathrm{K}^{+}$pump activity. ${ }^{33}$ Lipoperoxidation end product accumulation is not a simple tracer of oxidative stress but it can have a major role in the pathogenesis of Parkinson disease. HNE accumulation could be due to the impairment of the aldehyde detoxification system, among which are ALDH 1 and 2, both isoforms expressed in substantia nigra dopamine neurons. ${ }^{34}$ Null mice for ALDH1 and ADLH2 have high levels of $\mathrm{HNE}$ and $\mathrm{HNE}$-adducted proteins in the midbrain, and this could be directly correlated to a reduction in dopamine and metabolites in the striatum. Lastly, a recent study clearly demonstrates that intracerebral injection of HNE results in neurodegeneration. ${ }^{35}$ Therefore, HNE can impair key areas in the brain, leading to neuronal cell death. Carnosine, as a carbonyl scavenger and antioxidant, can provide protection against HNE and decrease neurodegenerative disorders, ${ }^{36}$ but its action is not limited to HNE-dependent damage.

Cardiovascular diseases. HNE has been shown to be implicated in cardiovascular diseases, as an accumulation of HNE was described in atherosclerotic lesions in both human and animals. LDLs can be oxidized by ROS from vascular cells. This leads to the formation of HNE and other aldehydes. HNE can form adducts with apoB. OxidizedLDL bound to HNE-adducted apoB has a lower affinity for the apoB/E receptors that are expressed in most cell lines, except macrophages. Such modified LDLs are then reoriented toward scavenger receptors, expressed at the surface of macrophages and smooth muscle cells, leading to the 
formation of foam cells. The accumulation of foam cells promotes apoptosis induction and the formation of lipid cores. $^{37}$ The subsequent atheromatous plaque formation involves macrophage infiltration and activation of smooth muscle cells leading to fibrogenesis. HNE can particularly form adducts with PDGFR (platelet-derived growth factor receptor) in atherosclerotic aortas and the use of the antioxidant hydralazine prevents HNE-related adduction and slows the progression of the disease. ${ }^{38}$

HNE could also promote chronic inflammation by stimulating the expression and the synthesis of MCP-1 (monocyte chemotactic protein 1) and TGF $\beta$ (transforming growth factor $\beta$ ) in macrophages and smooth muscle cells. ${ }^{39}$ Moreover, HNE could affect the vascular cells' barrier integrity, leading to apoptosis of endothelial cells. ${ }^{40,41}$

$\mathrm{HNE}$ is also involved in myocardial infarction. After the ischemia/reperfusion sequence, ROS are produced and accumulated. They promote the generation of HNE, which can then disrupt the actin cytoskeleton, alter $\mathrm{Ca}^{2+}$ homeostasis and trigger cardiomyocyte cell death. ${ }^{42}$

Metabolic syndrome. Metabolic syndrome is a combination of metabolic disorders that may include impaired glucose tolerance, insulin resistance, dyslipidemia, obesity and liver disease. In diabetes, pancreatic $\beta$ cells have been described to be highly sensitive to ROS. Therefore, HNE, which can trigger $\beta$ cell apoptosis, may induce glucose intolerance and the development of diabetes. ${ }^{24}$

In non-alcoholic fatty liver disease (NAFLD), the persistent JNK (c-jun N-terminal kinase) activation by oxidative stress and HNE in hepatocytes induces cell death. ${ }^{43}$ In alcohol liver damage, protein modifications (adduction, haptenation) by aldehydes modify self-proteins and thus, stimulate the production of auto-antibodies and autoimmune reactions. ${ }^{2}$ More precisely, during the early phases of cirrhosis, antibodies against serum albumin adducted to MDA and HNE are detected in patients' sera. The antibody levels are higher in heavy drinkers with cirrhosis or extensive fibrosis than in those with fatty liver only. The formation of antigens derived from lipid peroxidation contributes to the development of immune responses associated with alcoholic liver disease. ${ }^{44}$ Finally, the importance of HNE in ethanol-induced steatosis was underlined by some studies relative to TNF $\alpha$ (tumor necrosis factor alpha)-induced apoptosis. Ethanol feeding appears to induce HNE-protein adducts, linked to an increase in TNF $\alpha$ secretion and apoptosis induction (TUNEL-caspase activation). When mice are coexposed to ethanol and antioxidants such $\mathrm{N}$-acetyl-cysteine (NAC), ${ }^{45}$ the decrease in HNE-protein adducts protects hepatocytes against cell death.

When hepatotoxicity is induced by chemical treatments in vivo, such as acetaminophen, the supplementation with S-adenosylmethionine protects the liver, prevents lipoperoxidation and GSH (glutathione) depletion and decreases centrilobular necrosis. ${ }^{46}$

Cancer. Redox homeostasis appears to be modified in cancer cells. ${ }^{47}$ The activation of oncogenes, the modification of energy metabolism, the mitochondrial dysfunction and the inflammation in the surrounding tissues lead to the increase in oxidative stress during carcinogenesis. However, the level of lipid peroxidation products in cancer cells is still debated. On one hand, early studies have shown low HNE levels in tumor tissues compared with healthy tissues. ${ }^{48-50}$ Low levels of HNE have been shown to be linked with a decrease in TGF $\beta 1$, a cell growth inhibitory cytokine known to be downregulated in a large number of human malignant colon tumors. The decrease in TGF $\beta 1$ has been correlated with an increase in carcinogenesis progression. ${ }^{51}$ On the other hand, some studies have demonstrated increased HNE levels in cancer tissues, ${ }^{25,52,53}$ and the HNE-adduct levels seem to be positively correlated to progression in both the grade of malignancy in brain cancers ${ }^{54}$ and the stages of hepatitis. ${ }^{55}$ Several hypotheses can be formulated to explain these divergences. First, the considerable heterogeneity of tumor cells implies different patterns of the lipid composition of membranes, with an increase in cholesterol and a decrease in PUFA content and therefore, a lower formation of HNE. ${ }^{56}$ Moreover, tumor cells can exhibit higher expression of detoxification enzymes and antioxidant proteins that permit a better HNE extrusion. ${ }^{57}$ Finally, different grades of the tumors studied with a low lipoperoxydation level have also been related to better proliferative potential. ${ }^{58}$

In the case of the carcinogenic effect of HNE as an exogenous compound, during the promotion of colorectal carcinogenesis by heme iron, HNE has been shown to be produced in the colon lumen. It has been shown that normal cells are highly sensitive to HNE, whereas preneoplastic cells are resistant. Thus, it can promote the positive selection of preneoplastic cells, finally leading to the development of colorectal cancer. ${ }^{14,59}$

As HNE can bind to guanine bases, it is mutagenic and genotoxic in vitro $^{60}$ and that might contribute to cancer initiation in vivo. ${ }^{61}$ It may also contribute to cancer promotion by inhibiting DNA repair ${ }^{62}$ or by promoting inflammation. ${ }^{6}$

A strong induction of oxidative stress with HNE formation in advanced stage cancer cells using natural and chemical drugs is a therapeutic strategy to trigger apoptosis. ${ }^{47}$ However, the acquisition of high antioxidant defense by cancer cells can also be a limiting factor for radiotherapy and chemotherapy. The use of a combination of drugs that target cancer cells and break down their antioxidant defenses can be a promising strategy to specifically induce cell death in cancer cells. ${ }^{47}$

Diseases occurring due to oxidative stress notably involve cell death processes, such as apoptosis. Our goal here is to focus on the HNE regulation of cell death/survival, related to oxidative stress-dependent disorders. These relationships are complex. First, apoptosis can be mediated by different pathways and is not the only process of the induction of cell death. Second, HNE has dose-dependent effects, and the consequences on the cell are strongly modulated by the ability of the oxidative stress defenses to metabolize HNE. Lastly, based on the intrinsic nature of the cells, their responses regarding $\mathrm{HNE}$ could be multiple and in favor of the emergence of pathologies.

\section{HNE: a Serial Killer}

Apoptosis is a major pathway of cell death characterized by cell shrinkage, cell surface blebbing, chromatin condensation 
and DNA fragmentation. It is an active and programmed cell death that occurs via two main pathways: the extrinsic pathway, also called 'death receptor pathway' and the intrinsic pathway or 'mitochondrial pathway'. HNE can directly induce apoptosis but it can also be a mediator of apoptosis, as it can be generated by ROS (hydrogen peroxide), heat stress, ${ }^{63}$ UVA irradiations ${ }^{64}$ and pro-oxidant compounds like ethanol. ${ }^{65}$

HNE induces the extrinsic apoptotic pathway. The extrinsic apoptotic pathway transmits a death signal from the cell surface to the intracellular compartment and is initiated by the activation of death receptors like receptors of TNF, Fas/CD95 or TRAIL (TNF-related apoptosis-inducing ligand). Basically, the canonical signaling pathway involves the binding of their respective cytokines (TNF $\alpha$, Fas Ligand (FasL), TRAIL), which triggers the aggregation of the receptors and the recruitment of adaptator proteins leading to the activation of initiator caspases (8 and 10). Executioner caspases ( 3 and 7 ) are then activated, promoting the cleavage of many substrates contributing to the execution of apoptosis, but the recruitment of the signaling proteins is dependent on the nature of the death receptor. As a relevant example for HNE-mediated apoptosis, the binding of FasL on its receptor Fas triggers its aggregation that leads to the formation of DISC (death-inducing signaling complex) involving the adaptator protein Fas-associated protein with death domain (FADD) and pro-caspase $8 / 10 .^{66}$ The promiscuity of all these proteins triggers the activation and the autocatalytic cleavage of caspase 8/10. Consequently, the caspasedependent cascade leads to apoptosis.

In the case of the impact of HNE on the extrinsic pathway, in the eye, it promotes the expression of Fas, allowing a sensitization of the lens epithelial cells to apoptosis when FasL is present in the microenvironment as a soluble cytokine or expressed on the neighboring in cells' membrane as a transmembrane form. The induction of Fas by HNE is associated with JNK activation and apoptosis induction ${ }^{67}$ but the modalities of Fas transcriptional regulation are still to be established. The links between HNE and Fas are of interest because they rely on physiological levels of HNE. One strategy to modulate basal HNE concentrations has been developed by the Awasthi's group, based on the overexpression or the downregulation of GSTA4, the main HNE-detoxifying enzyme. When human GSTA4 was overexpressed in lens epithelial cells, the levels of HNE decreased and Fas was strongly downregulated. ${ }^{68}$ Moreover, when GSTA4 was downregulated or invalidated in vivo in mice, the levels of HNE were increased ${ }^{68}$ and Fas expression was induced. ${ }^{67}$ The basal levels of HNE in the cell can then contribute to their sensitivity or their resistance regarding FasL stimulation or even HNE. For this latter point, it is worth noting that Fas-deficient lens epithelial cells are resistant to HNE -induced apoptosis according to the mechanism detailed below.

The main pathway of Fas-signaling activation by HNE appears to be DISC-independent ${ }^{67,69}$ (without caspase 8 and FADD). Indeed, HNE can induce Fas-dependent apoptosis in pro-caspase 8 -deficient Jurkat cells. ${ }^{69}$ The hypothetical mechanism can be dependent on the capacity of HNE to form protein adducts. The HNE-adduct formation with a membrane receptor could mimic ligand-cell surface receptor binding, which could then activate the related-signaling pathway. This model was proposed for EGFR (epidermal growth factor receptor) or PDGFR. ${ }^{23}$ Fas is a death receptor with a cysteine-enriched extracellular domain and HNE has been shown to form adducts with Fas in vitro. ${ }^{69}$ The binding of HNE on Fas seems primordial, as cell pretreatment with a Fas antagonizing antibody induces resistance to apoptosis triggered by HNE.

HNE activation of Fas without DISC involvement is enabled by the downstream activation of ASK1 (apoptosis signalregulating kinase 1 ), JNK and caspase 3 . Interestingly, HNE also activates a negative feedback on Fas activation, by a mechanism involving Daxx (death domain-associated protein). Daxx is a nuclear protein which is associated with DNA-binding transcription factors involved in stress response and known to repress their activities. ${ }^{70}$ After its export from the nucleus to the cytosol, it can interact with Fas. The pathway involving ASK1, JNK and caspase 3 is then inhibited and leads to the repression of apoptosis. ${ }^{71}$ Daxx silencing induces an exacerbation of the HNE-induced apoptosis suggesting the prominent role of Daxx as a negative regulator of apoptosis, thus avoiding massive cell death. ${ }^{69}$ In 2010, the Awasthi's team demonstrated that HNE induced both expression of Fas and Daxx. HNE can create covalent links with Daxx via some histidine residues, and in this way increase its export from the nucleus to the cytoplasm. The Fas-Daxx binding could have a negative effect on the ASK1-JNK signaling pathway and apoptosis induction. These mechanisms could be relevant for apoptosis induction by oxidative stress. If the stress is moderate, the couple Daxx-Fas limits apoptosis induction, whereas if the oxidative stress is massive, the pathway mediated by Fas-ASK1 and JNK is major and triggers massive cell death. Taking into account that HNE is diffusible, this negative loop can preserve the tissue integrity, as has been observed in vivo. ${ }^{72}$ This self-regulatory function for Daxx has also been described in Fas-dependent apoptosis after UV- and doxorubicin treatments, conditions that are commonly associated with oxidative stress. However, the role of Daxx as an apoptosis regulator is still controversial. ${ }^{70}$ On the contrary, some studies demonstrate that Daxx binding on Fas promotes cell death: the process being independent of DISC formation. ${ }^{73}$ The differences in Daxx activity as a pro- or an anti-apoptotic factor can arise from the fact that Daxx has a role both in the cytosol and in the nucleus. The complexity of its regulation can also depend on the cell types and the relative importance of Fas and JNK pathways. Lastly, contributing to the negative feedback of apoptosis regulation, it has also been shown that HNE treatment induces the downregulation of pro-apoptotic-associated genes such as IER3 (immediate early response 3), TRAF3 (tumor necrosis factor-a receptor-associated factor 3 ) in RKO human colorectal carcinoma cells, ${ }^{74}$ CAD (caspase-activated DNAse), FAST K (Fas-activated serine/threonine kinase) and DFF45 (DNA fragmentation factor 45) in ARPE-19 human retinal pigmental epithelium cell line. ${ }^{75}$

HNE-induced extrinsic apoptosis has been described in various cell models, and especially in human eye epithelial cell lines (HLE-B3 and ARPE-19) and leukemia cell lines (Jurkat, CRL2571). These models are very relevant from a clinical 
point of view. Retina is one of the organs most sensitive to HNE, first, because of the high consumption of oxygen by photoreceptors that generates high levels of ROS, and because its membranes contain one of the highest percentages of PUFAs. The pathways by which HNE induces apoptosis are relevant for understanding retinal damage and vision degradation in retinopathies. ${ }^{76}$ In the case of leukemia cells and HNE-induced extrinsic apoptosis, numerous studies have shown that patients at all stages of illness present an abnormally elevated oxidative status, ${ }^{77}$ whereas elevated ROS levels have been detected in chronic and acute myeloid malignancies. The efficacy of molecules with therapeutic potential, such as dithiolethione, ${ }^{78}$ was shown using HNE as a potent oxidative stress mediator in derived leukemia cell lines. These preventive strategies are based on HNE scavenging or on an improvement of cell detoxification regarding HNE (see last part of this review). The extrinsic apoptotic pathway mediated by HNE is summarized in Figure 2.

HNE induces the intrinsic apoptotic pathway. The intrinsic apoptotic pathway, also called the mitochondrial pathway, is the major apoptotic pathway highly conserved in vertebrates. Mitochondria have the capacity to integrate the pro-apoptotic signals from a large panel of extra- and intracellular stimuli (oxidative stress, starvation, radiation, DNA damage and toxins). These signals lead to mitochondrial outer membrane permeabilization (MOMP), which results in the release of different factors from the intermembrane space into the cytosol. Depending on the nature of the released pro-apoptotic factors, the mitochondria trigger caspase-dependent or caspase-independent apoptosis. The release of cytochrome $c$ (cyt $c$ ) leads to the formation of the apoptosome, with the cytosolic proteins APAF1 (apoptosis protease-activating factor-1) and the initiator caspase 9. This complex initiates the autocatalytic cleavage of caspase 9 , its activation and the subsequent cleavage of executioner caspases such as caspases 3, 6 and 7. In the cytosol, some endogenous caspase inhibitors like IAP (inhibitor of apoptosis protein) prevent caspase activation. The mitochondrial release of the proteins Smac/Diablo (second mitochondrial activator of caspases) and Omi/htrA2 prevents XIAP (Xlinked (AP) activity and by this means mediates caspase activation. Mitochondria are also major actors in caspaseindependent apoptosis. This process also involves MOMP but the release of killer proteins like AIF (apoptosis-inducing factor) and endonuclease $G$ from the mitochondria to the nucleus triggers a caspase-independent DNA fragmentation. ${ }^{79}$

There are some examples showing that HNE can induce mitochondria-dependent apoptosis: mouse leukemic macrophage cell line ${ }^{80}$ exposed to HNE show the classical hallmarks of intrinsic apoptosis such as anti-apoptotic protein downregulation, pro-apoptotic protein upregulation, cyt c/AIF release and DNA fragmentation. During muscle cell apoptosis in age-related sarcopenia, the increase in HNE generation leads to anti-apoptotic protein inactivation and JNK and caspase $2 / 9$ activation. ${ }^{81}$ The same observation was made in the RKO colon cancer cell line ${ }^{82}$ and in the PC12 neuronal cell line. ${ }^{83}$

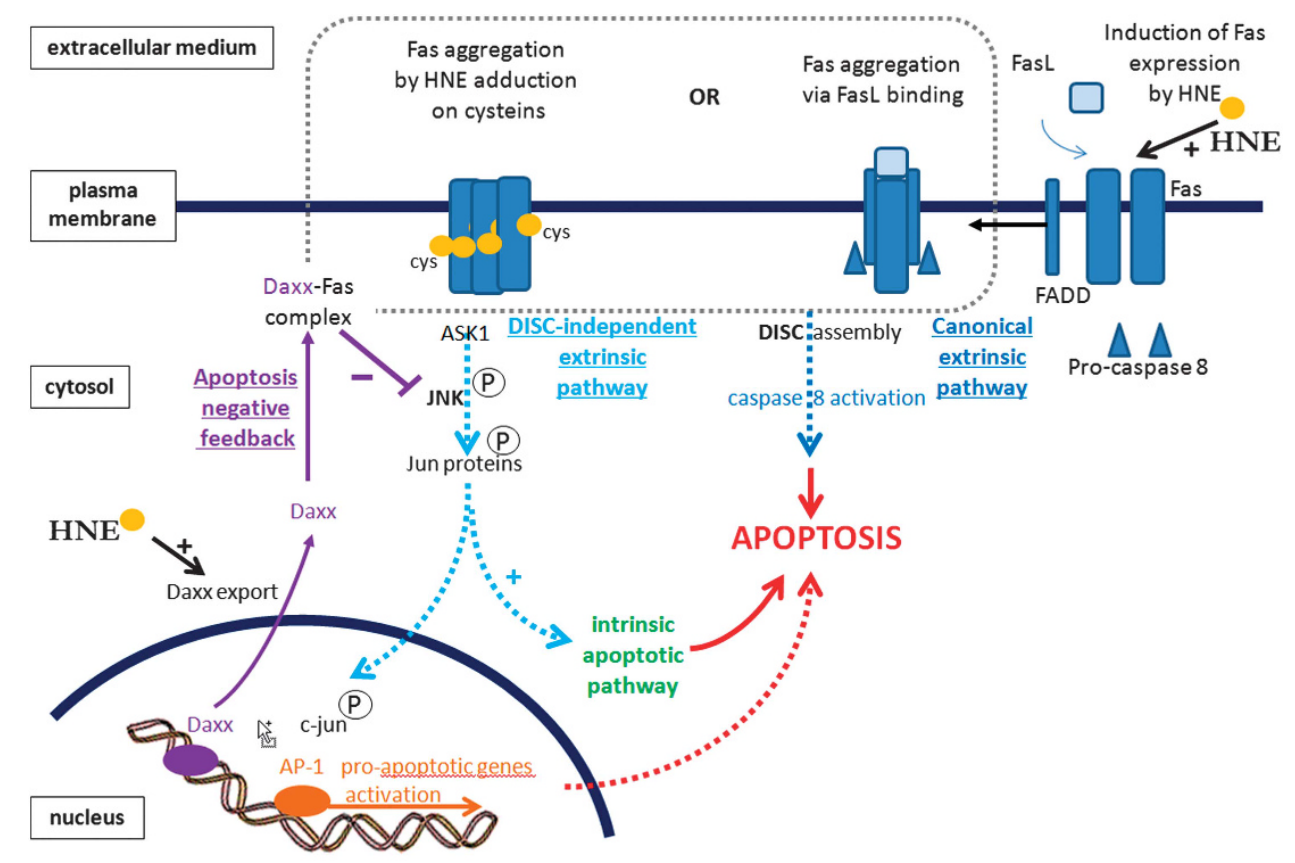

Figure 2 Main extrinsic apoptotic pathway induced by HNE and Daxx-dependent-negative feedback. Extrinsic cell death can be mediated by Fas receptor, via the induction of Fas expression at the membrane or the direct binding of HNE on Fas, leading to its aggregation, independent on FasL and DISC formation. This latter process involves the ASK1/JNK pathway triggering AP-1-dependent transcription. In purple is represented the negative feedback with Daxx, modulating Fas-apoptotic signal. AP-1: activator protein 1; ASK1: apoptosis signal-regulating kinase 1; Daxx: death domain-associated protein; FADD: Fas-associated protein with death domain; FasL: Fas ligand; HNE: hydroxynonenal; and JNK: C-Jun N-terminal kinase 
The early events upstream of mitochondria targeting are diverse and are highly dependent on the initial stimulus. Cardiomyocytes treated with physiological concentrations of HNE show a progressive depletion in their mitochondrial bioenergetic reserve that leads to respiratory failure and cell death. This pathway is supposed to be important in myocardial pathologies where HNE could contribute to tissue damage by the increase in oxygen consumption, the subsequent mitochondrial failure and finally the depletion of energetic capacity. ${ }^{84}$ In cultured hippocampal neurons, HNE exposure can cause impairment of ATPase activities and a subsequent abnormal increase in $\left[\mathrm{Ca}^{2+}\right]$. This disruption acts as an apoptotic signal. Whatever the apoptotic stimulus, the $\mathrm{Bcl} 2$ (B-cell lymphoma 2) protein family has the role of an integration crossroad. Some of $\mathrm{Bcl} 2$ family members are

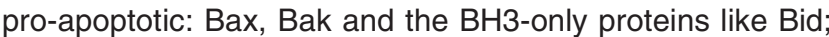
whereas others are anti-apoptotic such as Bcl2, Mcl1 or $\mathrm{Bcl}-\mathrm{xl}$. The balance between these pro-apoptotic and antiapoptotic factors determines the fate of the cell. Upon a stress signal, the pro-apoptotic Bax and Bak proteins multimerize and are inserted into the mitochondrial outer membrane, forming pores at the origin of the MOMP. The phosphorylation of $\mathrm{Bcl} 2$ at its interaction site with the other members can modulate its activity. HNE has recently been shown to stabilize the interaction between $\mathrm{Bcl} 2$ and IKK (inhibitor of kappa $\mathrm{B}(\mathrm{l} \kappa \mathrm{B})$ kinase). The IKK is then able to phosphorylate $\mathrm{Bcl} 2$ on its critical site, thereby altering its anti-apoptotic function. ${ }^{85}$

Moreover, HNE can directly affect mitochondrial integrity. Mitochondrial membranes contain a critical phospholipid called cardiolipin. Cardiolipin oxidation by cyt c can produce HNE. $^{86}$ It has been shown that cardiolipin oxidation is necessary for the subsequent steps of intrinsic apoptosis. It activates MOMP and enables the activation of apoptogenic $\mathrm{Bcl} 2$ proteins. Finally, HNE can directly affect the cellular redox status by depleting $\mathrm{GSH}$, which can then induce a mitochondrial crisis with mitochondrial ROS production ${ }^{87}$ and subsequent activation of caspases. ${ }^{88} \mathrm{HNE}$-induced apoptosis can then be prevented by mitochondrial respiratory chain inhibitors such as rotenone or stigmatellin. ${ }^{89}$

The intrinsic apoptotic pathway activated by HNE is summarized in Figure 3.
HNE and JNK activation during apoptosis. Depending on the cell type, HNE-induced apoptosis can involve both extrinsic and intrinsic pathways, but the respective contribution of the two pathways remains elusive. However, there is some evidence to show that strong JNK activation is a common step in HNE-induced programmed cell death. ${ }^{90}$

Generally, JNK is known to have a central role in both intrinsic and extrinsic pathways. This kinase belongs to the mitogenactivated protein kinases (MAP kinases) family and can be activated in response to diverse stimuli such as oxidative stress, lipopolysaccharides, TNF $\alpha$ or endoplasmic reticulum (ER) stress. After being activated by phosphorylation, JNK can translocate to the nucleus and then transactivate transcription factors (c-jun and c-myc) that regulate the expression of proapoptotic genes such as FasL, Bak and TNF $\alpha .{ }^{91}$

HNE was shown to interact directly with JNK by forming adducts. This leads to nuclear translocation of JNK in human hepatic stellate cells. ${ }^{92}$ Moreover, HNE-induced apoptosis in neuronal PC12 cells is clearly mediated by the JNK pathway and not by other MAP kinases p38 or ERK pathways. ${ }^{93,94}$ In sympathetic neurons, the specific neuron-associated JNK3 is activated during HNE-induced apoptosis. This is accompanied by $c$-jun phosphorylation and these effects can be suppressed in JNK3-deficient neurons. ${ }^{95}$ The pretreatment of leukemic cells with JNK inhibitor makes these cells resistant to HNE-induced apoptosis. ${ }^{69}$ Finally, well-known antioxidant molecules like resveratrol and piceatannol prevent HNE-induced apoptosis by blocking the JNK pathway and subsequently c-jun phosphorylation and AP-1 signaling. ${ }^{96,97}$ Further experiments should be carried out in order to evaluate the role of JNK in HNE-induced apoptosis to clarify the orientation of the cell death pathway: extrinsic pathway by the regulation of $c$-jun/AP-1 signaling or intrinsic pathway by modulation of mitochondrial proteins.

HNE and p53: relationship between genotoxicity and cell death. Tumor protein 53 (p53) is a tumor suppressor and a transcription factor that regulates gene expression related to the cell cycle, DNA repair and apoptosis. p53 is activated upon DNA damage and oxidative stress to protect and repair the cell, but if the stress or damage reach a threshold, p53 triggers cell death.

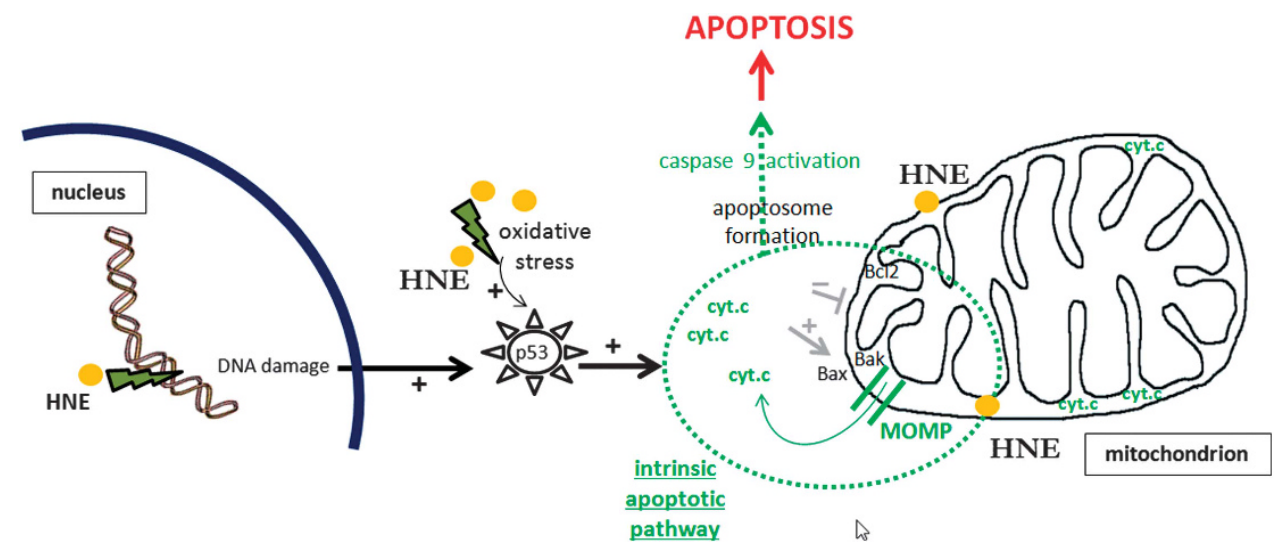

Figure 3 Intrinsic apoptotic pathway is induced by oxidative stress, p53 and mitochondrial membrane disturbances. cyt.c: cytochrome c; HNE: hydroxynonenal; and MOMP: mitochondrial outer membrane permeabilization 
Sharma et al. ${ }^{98}$ showed that exogenous HNE results in the phosphorylation of p53 (on Ser 15) and its nuclear translocation in retinal epithelial cells. Such activation is involved in apoptosis induction. On the other hand, the simple accumulation of p53 in HNE-treated mouse macrophages was not associated with apoptosis induction. ${ }^{80}$ As the degradation of p53 is proteasome-dependent and as HNE is able to inhibit proteasome activity, ${ }^{20}$ one may suggest that p53 accumulation is the result of defective proteolysis rather than an active stabilization of p53. Moreover, HNE is known to be genotoxic $^{99,100}$ and the activation of p53 upon HNE-mediated DNA damage appears relevant in a context of apoptosis, to trigger the expression of Bax, caspase 3 and inhibit Bcl2.

A recent study has examined the conformational modifications of p53 in NDD. ${ }^{101}$ It showed that the formation of HNEp53 adducts did not affect the native conformation of p53, unlike nitration. The nitrated and so unfolded p53 directly decreases its pro-apoptotic activity and favors the survival of damaged neurons. Therefore, in this study, HNE adduction did not have a major impact on p53 function but could constitute an aggravating factor.

On the contrary, as p53 is a master regulator of the antioxidative response, it can directly act on HNE-induced toxicity: a study performed on p53 $(-/-)$ mice brains showed that the lack of p53 reduced endogenous HNE levels and protein adduction. ${ }^{102}$ Consequently, p53 should be involved in the generation of HNE and this positive feedback can have a major role in NDD in which the levels of p53 bound to $\mathrm{HNE}$ are elevated and correlated to neuronal cell death. ${ }^{103}$

\section{Other Pathways of Cell Death: One Killer, Several Weapons}

HNE-induced apoptosis appears to be caspase-dependent. However, cells treated with caspase inhibitors such as z-VAD-FMK or DEVD-FMK do not present a completely rescued phenotype, ${ }^{104}$ suggesting the involvement of caspase-independent apoptotic mechanisms.

Calpain-mediated cell death. Intracellular $\mathrm{Ca}^{2+}$ levels are tightly regulated and $\mathrm{Ca}^{2+}$ is stored mainly in the $\mathrm{ER}$ and mitochondria under normal conditions. ROS attack can lead to the loss of ER membrane integrity, which is associated with a release of $\mathrm{Ca}^{2+}$ into the cytoplasm. Thus, lipid oxidation and notably through $\mathrm{HNE}$, can be a signal for $\mathrm{Ca}^{2+}$ mobilization ${ }^{105}$ and subsequent calpain activation. Calpain is a $\mathrm{Ca}^{2+}$-dependent protease, located in the cytosol as an inactive precursor. In response to increased levels of cytosolic $\mathrm{Ca}^{2+}$, it translocates to the intracellular membranes and is activated by autocatalytic hydrolysis. Heat shock protein 70 (Hsp70), a chaperone protein and $\alpha$-fodrin, a structural cystoskeletal protein, are known to be common substrates for calpains. Calpain-dependent Hsp70 cleavage is associated with lysosomal membrane permeabilization (LMP), which leads to the release of proteases called cathepsins into the cytoplasm, then triggering cell death. Actually, it has been shown that HNE induces $\alpha$-fodrin cleavage ${ }^{106}$ and also the upregulation of Hsp70 expression and its carbonylation. ${ }^{69,107}$ This post-translational modification is necessary for its cleavage by calpain, suggesting the participation of calpains in the cell death cascade. ${ }^{107}$ This link is still to be clearly established.

ER stress, proteasome inhibition and apoptosis induction. Because of its propensity to aggregate with proteins in the cell, HNE triggers the accumulation of protein aggregates in the cell that can overcome the proteasome. This can be amplified by a direct inhibition of proteolytic subunits: specific subunits of the $20 \mathrm{~S}$ proteasome are targeted by HNE and the thus modified proteasome has impaired peptidase activity. ${ }^{20,108}$

Moreover, ER stress and the activation of the unfolded protein response (UPR) are triggered when the ER is overwhelmed and cannot manage the processing and the folding of newly synthesized proteins and the elimination of unfolded or misfolded proteins. In atherosclerotic plaques, the protein modifications by LPO secondary products like aldehydes affect protein conformation and their activities. The accumulation of misfolded and undergraded proteins can lead to ER stress. If the ER stress is prolonged, it can turn into apoptosis induction. HNE was described as inducing ER stress and an UPR in human endothelial cells that had HNE-adducts with proteins colocalizing with ER. ${ }^{109}$ These adducted proteins directly affect ER function, especially protein disulfide isomerase. ${ }^{110}$ In support of this idea, it was shown that the folding of protein to allow optimal formation of disulfide bonds is highly redox-dependent in the ER. ${ }^{111}$ Thus, the accumulation of misfolded proteins with HNE-adducts in ER could compromise cell survival. The UPR is an adaptive process but the non-re-establishment of cell homeostasis strongly compromises tissue integrity and can initiate or promote pathologies.

Necrosis. To understand the effects of HNE, it is necessary to highlight the importance of the doses tested in each experiment. In the experiments of Chaudhary et al. ${ }^{107}$ on HepG2 cells exposed to $5-40 \mu \mathrm{M}$ of HNE, the cells died by apoptosis, but the same cells exposed to 80-100 $\mu \mathrm{M}$ HNE underwent necrosis, a non-programmed and deleterious form of cell death in which organelles are damaged and the plasma membrane disrupted. Respectively $31.8 \%$ of the cell population that was exposed to $80 \mu \mathrm{M} \mathrm{HNE}$ and $55.4 \%$ for the $100 \mu \mathrm{M}$ HNE treatment died by necrosis. Similarly, necrosis is induced by HNE at $100 \mu \mathrm{M}$ in HeLa cells ${ }^{112}$ as well as in colorectal cell lines. All these in vitro data suggest a dose-dependent effect of HNE, with the induction of apoptosis at low doses and necrosis induction at high doses. The level of antioxidant defense has also to be taken into account (see chapter 7). However, because of the difficulty of quantifying free HNE in vivo, the data are limited concerning the possibility that such high concentrations of $\mathrm{HNE}$ could be reached in vivo and notably in oxidative stress-related pathologies. ${ }^{10}$

Iron-regulated cell death. Among the emerging cell death pathways closely related to HNE, iron-regulated cell death carves out a growing place. Ferritin is a protein involved in iron storage. The endocytosis of ferritin into lysosomes induces the release of free redox active $\mathrm{Fe}^{2+}$ which promotes ROS formation and subsequent lysosomal LPO. 
This generation of HNE leads to LMP. HNE-adducts were also detected in the cytosol, suggesting the spreading of LPO from the lysosome to the cytosol. Moderate LMP can result in apoptosis, whereas the total loss of lysosomal integrity triggers necrosis. ${ }^{113}$ However, the involvement of HNE in the balance of apoptosis/necrosis has to be reconsidered in the light of the recent studies on a new ironregulated cell death mechanism called ferroptosis. ${ }^{114}$ This newly identified route of cell death is dependent not only on iron metabolism but also on fatty acid synthesis and cystine transport (involved in GSH synthesis). All these processes can be directly linked to HNE generation and to its detoxification-induced pathways. That is why further studies should be carried out to establish the importance of HNE in the cell sabotage leading to cell death. ${ }^{115}$

\section{HNE Self Limits Apoptosis: Keeping Cool Under Pressure}

Interestingly, HNE induces apoptosis but also initiates mechanisms that attenuate it. In respect to this latter aspect, the work by Jacobs and Marnett ${ }^{116}$ is particularly relevant. They demonstrated that the treatment of the RKO colorectal cancer cell line with HNE leads to a dose-dependent activation of HSF1 (heat shock factor 1), a transcription factor that protects cells against stress insults such as heat shock and oxidative stress. After HNE exposure, HSF1 is translocated from the cytoplasm to the nucleus and reduces HNE-induced apoptosis. The underlying mechanisms were identified by siRNA and overexpression, and they can be summed up as follow: first, HNE triggers the release of HSF1 from the regulator chaperones Hsp70 and Hsp90 (heat shock proteins), allowing its translocation to the nucleus. HSF1 activates the transcription of genes containing HSE (heat shock responsive element) via their promoters, such as Hsp40 and Hsp 70.1; the induced Hsp attenuates JNKdependent apoptosis signaling and stabilizes Bcl-xL. The protective activation of HSF1 in HNE-induced apoptosis was also confirmed in HepG2 cells. ${ }^{107}$ Further experiments have demonstrated that the stabilization of $\mathrm{Bcl} 2$ anti-apoptotic proteins (like $\mathrm{Mcl} 1, \mathrm{Bcl}-\mathrm{xL}$ and $\mathrm{Bcl} 2$ ) is dependent on the induction of BAG3 (Bcl2-associated athanogene domaine 3) that interacts with $\mathrm{Hsp} 70$ and $\mathrm{Bcl}-\mathrm{xL} .{ }^{117}$ The degree of protection gained by this pathway is thought to be superior to the protection afforded by the detoxification pathways like Nrf2. ${ }^{116}$

\section{HNE Assault: The Choice to Stay Alive... Under Conditions}

HNE as a cell cycle brake. The cell cycle is traditionally divided into four phases: G1, S, G2 and M, with a particular status for $\mathrm{G} 1$ cells, which can enter a resting state called G0. These quiescent cells represent the major part of the non-growing, non-proliferating cells in the organism. The transition from one cell cycle phase to another is regulated by CDK (cyclin-dependent kinase). Specific cyclins/CDK couples constitute checkpoints at each step of the cell cycle, and are influenced by pro-mitotic factors (like cdc25) and anti-mitotic factors (like cyclin-dependent kinases inhibitors). For an exhaustive review see Vermeulen et al. ${ }^{118}$

Several large scale studies performed using microarrays show that HNE is able to downregulate cell cycle promoting genes such as cell division cycle homologs (cdc20, cdc25), cyclins (A2, B1, B2, D1, F and K), topoisomerase II $\alpha$, DNA polymerase $\delta$, TGF $\alpha^{74,75} \mathrm{HNE}$ also upregulates some cell cycle-arresting genes such as Gadd34 (growth arrest and DNA damage) or cyclin G2. ${ }^{74}$ However, the induction of cell cycle arrest by HNE has been known for a long time. ${ }^{119,120}$ In HL60 cells, the way to limit HNE toxicity also seems to be based on the ability to stop cell cycle arrest in G0/G1 via the inhibition of cyclins D1, D2 and A and the hypophosphorylation of retinoblastoma protein $(R b)$. In 1998, Esterbauer et al. ${ }^{121}$ showed that treating the budding yeast Saccharomyces cerevisiae with HNE resulted in its temporary arrest in G1 phase. More recently, in prostate PC3 cells, HNE treatment was shown to trigger cell cycle arrest in G2/M, with dephosphorylation of cdc2. ${ }^{122}$ Finally, we have previously seen that HNE can self-limit its apoptosis by modulating Daxx activity. ${ }^{69}$ Moreover, Daxx is also known to interact with cell cycle regulatory proteins like HSF1, smad4 or p53. ${ }^{123}$ We can hypothesize that a Daxx-dependent-negative loop on HNEinduced apoptosis can also be dependent on the direct effect of Daxx on the cell cycle.

This ability of HNE to slow down cell proliferation at apoptosis-inducing concentrations can be interpreted as an alternative route to apoptosis, a possibility for slightly damaged cells attain self-rescue survival and for the tissue to maintain homeostasis in case of low grade injury.

Senescence. HNE-adducts are accumulated with aging in vivo and in vitro. ${ }^{124,125}$ Senescence is a process associated with aging. Senescent cells are metabolically active cells in which growth is arrested in transition between the $\mathrm{G} 1$ and $\mathrm{S}$ phases. As senescent cells, these cells can no longer replicate, cannot re-enter the cell cycle and are characterized by shorter telomeres. Telomeres are repetitive sequences localized at the end of eukaryotic chromosomes. The synthesis of telomeric repeats is necessary for DNA replication and is ensured by a ribonucleoprotein called telomerase, only expressed in regenerative tissues. The length of telomeres decreases at each cell cycle division and constitutes a marker of somatic cell aging. Telomerase activity is reported to be reactivated during carcinogenesis and cancer cells escape senescence. ${ }^{126}$

It is well-described that oxidative stress accelerates telomere loss due to a decrease in telomerase activity in vitro. ${ }^{127}$ It has been reported that HNE (at non-lethal low doses) can downregulate expression of hTERT (human telomerase reverse transcriptase), the catalytic subunit of human telomerase, in leukemia cells and colon cancer cells. More precisely, HNE inhibits c-myc (an activator of the hTERT promoter) and activates Mad1 (a repressor of the hTERT promoter). ${ }^{128}$ Moreover, the activity of hTERT upon HNE exposure was also studied in endothelial cells isolated from patients with coronary artery disease. In this study, chronic treatment with NAC (an HNE scavenger and also a cysteine supplier for GSH synthesis ${ }^{129}$ ) led to a decrease in HNE levels and an activation of hTERT. ${ }^{125}$ 
Telomere shortening is a main cause of cellular senescence but very few studies have been done to characterize HNE-induced senescence, independently of its action on telomeres. This alternative pathway of senescence is characterized by the activity of $\beta$-galactosidase in the cytoplasm, the expression of cell cycle regulatory proteins p16 and p21 and the hypophosphorylation of Rb. Very recent experiments have characterized HNE-induced senescence in the development of atherosclerotic lesions in the blood vessels. HNE is secreted by activated macrophages and then induces senescence in vascular endothelial cells. ${ }^{130}$ Senescence will be of a great interest in the future as a major HNE-mediated aging mechanism.

Autophagy. Autophagy is a process that governs catabolic reactions and especially the clearance of long-lived proteins and organelles. It is characterized by autophagosome formation when the edges of the membrane initially fuse together to generate a large vacuole containing diverse macromolecules and cellular structures that will fuse with lysosomal membranes. This leads to the degradation of the contents of the autophagic vacuole.

After oxidative stress and HNE generation, the HNE-protein Michael-adducts are accumulated in the cell, and autophagy is a mechanisms by which such defective proteins can be degraded. In vascular smooth muscle cells (VSMC), HNE was shown to induce autophagy $(50 \mu \mathrm{M}$ for $30 \mathrm{~min})$. This was characterized by cellular ultrastructural changes (identified by electron microscopy) and by the increase in LC-3-II levels (microtubule-associated protein 1 light chain 3 under the phosphatidylethanolamine-conjugated activated form). ${ }^{131}$ Such an induction could be dependent on mTOR inhibition through yet still unknown mechanisms. However, it appears that the inhibition of autophagy can trigger apoptosis, which supports the fact that autophagy is probably a defense system for survival.

Finally, the case of age-related macular degeneration is interesting because of the high specificity of the retinal pigment epithelium (RPE). This tissue is the site of high and permanent oxidative stress because the cells are prominent oxygen consumers and exposed to light. When LPO is high, it increases HNE adduction to proteins, ${ }^{132}$ among which are proteins of the photoreceptor outer segments (POS). HNEadducted POS proteins are much less degraded by lysosomes and global proteolysis is decreased in RPE cells. Regarding that point, Krohne et al. ${ }^{133}$ have demonstrated that HNE-adducted POS directly reduces autophagy in RPE cells, leading to apoptosis induction. ${ }^{134}$

Therefore, VSMC exhibit a more adaptative capacity to survive HNE and oxidative stress than RPE cells. ${ }^{135}$ Retinal cells cannot sustain autophagy during massive LPO and finally die. In this context, autophagy is clearly a defense mechanism against HNE-protein adducts to maintain cell survival.

\section{The Battle of Wills Between Detoxification and Death}

For HNE, the balance between cell death and cell survival is largely dependent on the cells' abilities to cope with oxidative stress and especially to detoxify HNE.
Nrf2 and the antioxidant defense. Nrf2 is a master gene of antioxidant response. Under normal conditions, Nrf2 is in the cytosol, complexed with its inhibitor, Keap-1 (Kelch-like $\mathrm{ECH}$-associated protein 1), which is an oxidant sensor. Cullin 3 ubiquitin ligase is attached to Keap-1 and is responsible for conjugating ubiquitin molecules to Nrf2, giving the signal to proteasome to degrade Nrf2 consecutively. ${ }^{136}$ In the presence of HNE, adducts on cysteines are formed in Keap-1 protein. This modifies the affinity of Keap-1 for Nrf2, which induces the release of Nrf2 and its export to the nucleus. ${ }^{137,138}$ The nuclear Nrf2 recognizes consensus cis sequences called EpRE (electrophile response element) sequences. These sequences are present in the promoter region of genes coding for a great number of detoxification enzymes. Nrf2 can also form a heterodimer with c-jun and act independently or in synergy to activate antioxidant gene expression. ${ }^{139}$ The main genes which are regulated by Nrf2 are those that code for HO-1, NQO1, xCT (glutamate/cystine transporter), GCL, GSTs, ALDH, thioredoxin reductase 1 (Trx1) and AKR. ${ }^{136}$

$\mathrm{Nrf} 2$ is a major sensor of oxidative stress, and the disruption of Nrf2 abrogates antioxidant signaling, leading to the accumulation of HNE. ${ }^{140}$ Its activation is protective against oxidative stress and aging in vascular cells. ${ }^{141}$ However, the Nrf2 pathway is also a way for cancer cells to survive in a prooxidant environment ${ }^{57}$ and represents an important factor of resistance regarding chemotherapies in cancer. ${ }^{18,142}$

Mechanisms of HNE detoxification. The half-life of HNE is less than $2 \mathrm{~min}$. This short half-life underlines the importance of HNE detoxification as a cell defense system against HNE cytoxicity.

The key enzymes involved in HNE metabolism are GSTs, ALDHs and AKRs. GSTs have a major role in HNE detoxification: ${ }^{143}$ isoforms GSTA4-4 and GST5-8 have high catalyzing activity and allow the conjugation of HNE with the reduced form of gluthatione. This favors GSH-HNE export outside the cell via RLIP76 (RalA-binding protein 16 encoded $76-k D a$ splice variant) and/or MRPs (see Figure 4). The conjugation of HNE to GSH is primordial to neutralize HNE reactivity with proteins but also with DNA.

The GSH-HNE conjugates can be metabolized by two types of enzymes. The ALDH superfamily contributes to their oxidation in 4-hydroxynonenoïc acid (HNA)-lactone-GSH (HNA: 4-hydroxynonenoic acid), whereas the AKR superfamily contributes to their reduction in DHN-GSH (DHN: 1,4-dihydroxy-2-nonene). ALDHs have a prominent role. They can be downregulated in some disorders such as Parkinson disease. The recent study by Kong et al. ${ }^{144}$ shows that ALDH1A1 is a major HNE-detoxification enzyme in PC12 cells. Its overexpression results in reduced HNE toxicity, and its inhibition is neurotoxic, with a high accumulation of HNEprotein adducts. Other isoforms of ALDH, such as mitochondrial isoforms (ALDH5A and ALDH2), can also be determinant in HNE-mediated cell death. ALDH5A was described as metabolizing HNE in the brain. ${ }^{145}$ Finally, HNE itself can also be reduced by $\mathrm{AOR}$ ( $\mathrm{NAD}(\mathrm{P}) \mathrm{H}$-dependent alkenal/one oxidoreductase), and the generated metabolites (oxidized or not) can diffuse across the plasma membrane. $x C T$ is the transporter subunit of the heterodimeric amino-acid 


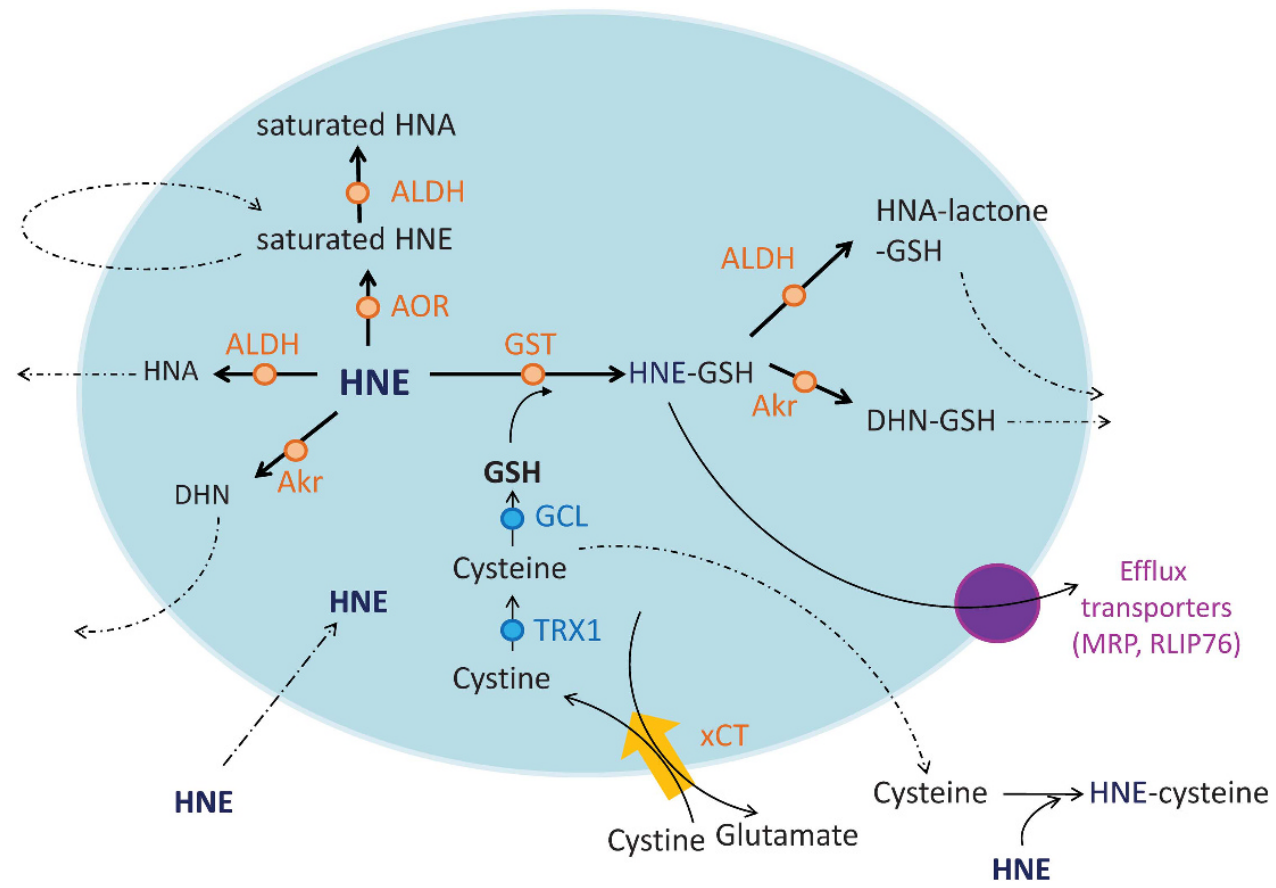

Figure 4 Putative pathways involved in HNE detoxification. The conjugation of HNE with glutathione by GST is the main step of detoxification. The renewal of cellular GSH pool is dependent on cysteine content, regulation by XCT. The oxidation pathway via ALDHs family is supposed to be activated when stress is moderate. The reduction pathway with AKRs family is thought to be activated in case of acute stress. DHN: 1,4-dihydroxy-2-nonene; HNA: 4-hydroxynonenoic acid; AOR: aldehyde oxydoreductase; AKR: aldo-keto reductase; GST: glutathione S-transferase; ALDH: aldehyde dehydrogenase; xCT: cystine transporter; MRP: multidrug-resistant protein; RLIP76: RalAbinding protein 16 encoded 76-kDa splice variant; and Trx1: thioredoxine reductase 1

transporter system xc-. It functions as an exchange transporter for cystine/glutamate, catalyzing the entry of cystine and the exit of glutamate at $1: 1$ ratio. Cystine is rapidly reduced by Trx into cysteine, which is the limiting substrate for GSH synthesis by $\gamma$-glutamylcysteine synthetase ( $\gamma$-GCS) and GSH synthetase. Cells can also excrete cysteine to neutralize extracellular HNE by the formation of HNE-cysteine conjugates. ${ }^{14}$

The enzymes involved in HNE detoxification are essential in regulating its biological role, and it is worth noting that HNE can positively regulate its own metabolism by activating Nrf2. According to a consensus model, HNE consumes the bioavailable $\mathrm{GSH}$ in the cell during the detoxification process to form non-reactive GSH-HNE. The decrease in GSH levels in association with Nrf2 activation triggers GSH synthesis by a positive feedback mechanism.

Links between detoxification and cell death. The ability of HNE to form adducts with proteins is the major deleterious event it promotes. According to this, the extent of apoptosis is directly dependent on the yield of HNE-adducts that are accumulated in the cells. ${ }^{112}$ These effects are absent when cells are pretreated with the HNE scavenger NAC. NAC acts as a precursor of GSH synthesis as well as a stimulator of the cytosolic enzymes involved in GSH regeneration. It mediates protection by direct reaction between its reducing thiol groups and ROS. ${ }^{146}$ So a part of its anti-apoptotic activity could be due to its ability to modify the GSH/GSSG redox balance in the cell in favor of the reduced form. Indeed GSH/GSSG balance in favor of the oxidized species (that is, GSSG) constitutes an important signal that could decide the fate of a cell. ${ }^{147}$ However, a large number of
HNE sequestering agents such carnosine or carnitine, act only by inhibiting the formation of HNE-protein adducts with a preferential formation of nontoxic scavenger-HNE adducts.

GSH conjugation is dependent on GST activity. The silencing of GSTA4-4 in human osteoarthritic chondrocytes increases HNE-induced cell death. ${ }^{148}$ On the contrary, HepG2 cells transfected with GSTA4-4 become resistant to HNE-induced apoptosis. ${ }^{149}$ The protective effect of GST overexpression against HNE-induced cell death has been observed in numerous cell lines (leukemia cells, retinal and lens epithelial cells). These cells acquire enhanced capacities to eliminate HNE, even after a prolonged treatment.

The entry of cystine, mediated by $\mathrm{xCT}$, is also crucial for detoxification and cell death. Ferroptosis cell death is notably dependent on $\mathrm{xCT}$ inhibition and iron-mediated oxidative stress (see 4.4). The involvement of HNE in this death process has still to be determined. ${ }^{114}$ In 2006, Li et al. ${ }^{150}$ generated a murine transgenic cell line with stable expression of the AKR isoform AKR7A5. These cells were four times more resistant to HNE than the parental cell line. Similarly, Matsunaga et al. ${ }^{151}$ showed that stable transfection of AKR1C15 suppressed apoptosis induced by HNE in endothelial cells. All these data underline the importance of AKRs in the prevention of HNE-induced apoptosis.

Targeting the inhibition of ALDH isoforms also diminish the abilities of the cell to survive deleterious concentrations of HNE. On the contrary, the use of a pharmacological ALDH2 activator notably decreases HNE-adducts, prevents cell death and induces angiogenesis in human endothelial cells exposed to $\beta$-amyloid peptides. $^{152}$ Finally, the cytosolic ALDH3A1 
isoform, specialized in HNE-detoxification in the ocular tissue, ensures protection of the cornea in the case of UV-induced oxidative stress. ${ }^{153}$

Finally, it is worth noting that detoxification, like apoptosis, mobilizes energy. The intrinsic bioenergetic reserve capacity is determinant for the cellular response. ${ }^{84}$ That is why the basal level of antioxidant enzymes cannot be sufficient to tackle a chronic exposure to HNE. The induction of Nrf2 and the adaptability of the metabolic reserve directly impact on the cellular resistance regarding $\mathrm{HNE}$ assault. The new data about the involvement of Nrf2 in the metabolic reprogramming in cancer cells ${ }^{154}$ open new perspectives concerning the regulation of antioxidant defenses in response to HNE but also about the global fitness of the cell after HNE exposure.

\section{Discussion}

HNE is a 'crossroads' molecule regulating signal transduction, gene expression, cell proliferation, stress-mediated signaling and cell death. However, the specificity of HNE is highly dependent on its concentration, the duration of exposure and the cell type. The threshold of oxidative stress tolerance is intrinsic to each cell type in a particular environment. At low concentrations (less than $5 \mu \mathrm{M}$ ), HNE has been reported to promote proliferation, ${ }^{155}$ and a silent stimulation of antioxidant responses by low levels of HNE (hormesis) can be protective $^{72}$ against more drastic assaults such as by carcinogens. ${ }^{142}$ At higher concentrations $(20-100 \mu \mathrm{M})$, HNE causes cell cycle arrest, ${ }^{120-122}$ disturbs differentiation ${ }^{156,157}$ and triggers cell death. The modalities of apoptosis induction pathways are governed by the inherent nature of the cell, prone or not to ROS generation, the level of antioxidant defense and the induction of HNE metabolizing enzymes (summarized in Figure 5).

However, precise methods for quantifying HNE are lacking in vivo. HNE is a highly reactive aldehyde and because of the multiplicity of its metabolites and adducts, we get just a trace of its presence and not the real value of its concentration in a free-reactive state. As an example, the in vitro data obtained in leukemia cell lines show that 15 -fold higher concentrations of $\mathrm{HNE}$ are required to induce apoptosis in primary leukocytes. ${ }^{158}$ We can conclude that primary cells are more resistant to HNE but we can also speculate as to whether the methods of cell culture modify the intrinsic antioxidant responses and the sensitivity toward HNE.

The pleiotropy of HNE targets (death receptors, mitochondria, p53 and transcription factors) makes it a real cell signaling molecule. Moreover, its half-life is longer than ROS such as $\mathrm{H}_{2} \mathrm{O}_{2}$ or $\mathrm{O}_{2}{ }^{-}$; HNE is therefore a good signal propagator that leads to the cellular sabotage, fatal for cells. Interestingly, physiological levels of HNE are also able to affect the expression of genes involved in cell adhesion, cell cycle control, proliferation, cell growth and apoptosis. ${ }^{19}$ Thus, we should consider not only intracellular HNE concentrations after diverse stimuli/exposure but also the basal level inherent to the cell.

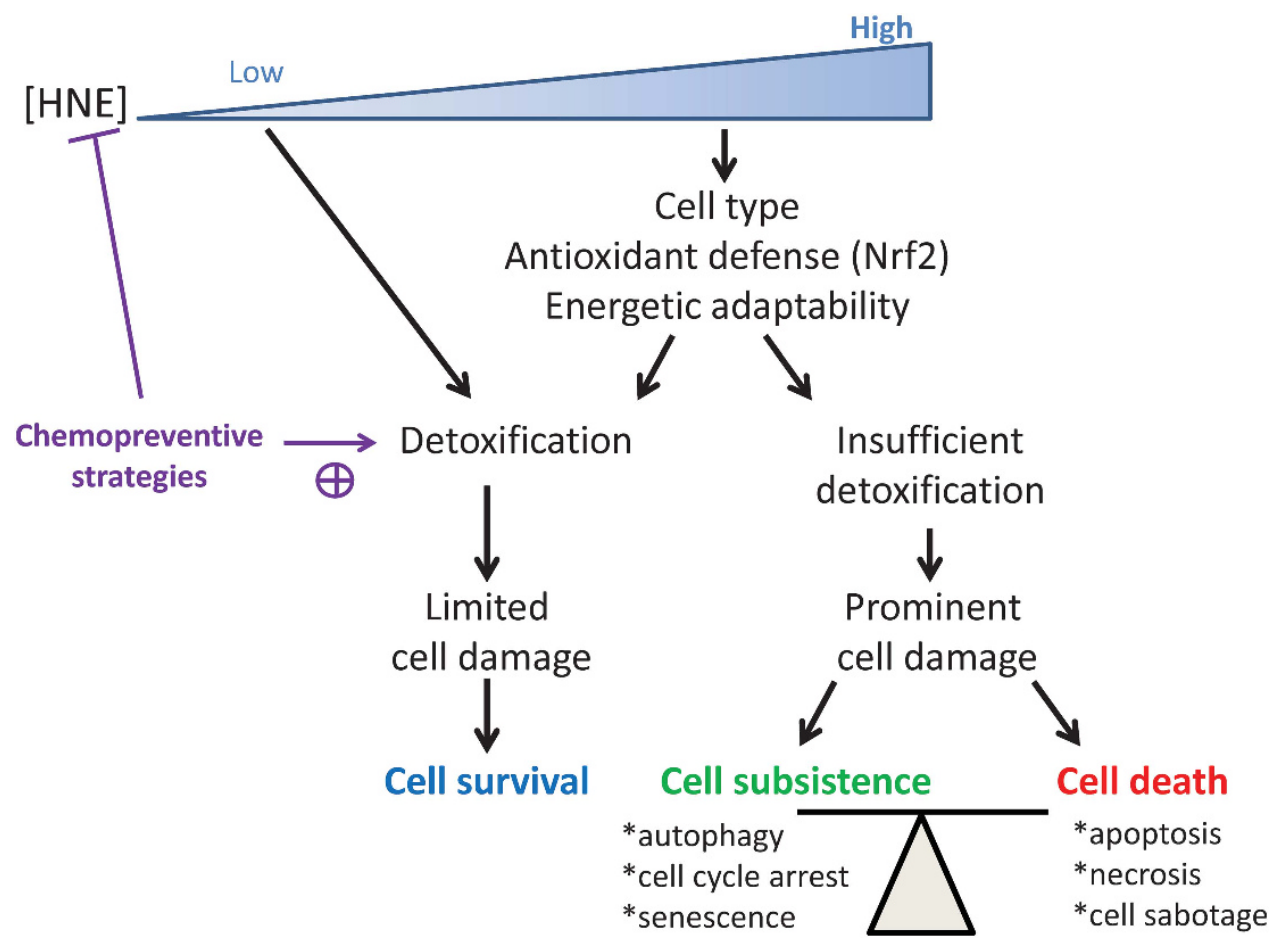

Figure 5 Summary of cell fate upon HNE exposure. When a cell is exposed to a low dose of HNE, HNE can be removed by detoxification processes and the viability is not compromised. Upon a high dose of HNE, the response will depend on the capacity of the cell to eliminate HNE by detoxification. This capacity is controlled by three parameters: the cell type, the antioxidant defense (notably Nrf2) and the energetic adaptability. If the damages are important, the cells can only 'subsist' by autophagy; senescence or cell cycle arrest. Otherwise, cell death is induced according to different pathways like apoptosis, necrosis or atypical cell death, sum up as 'cell sabotage'. Chemopreventive strategies can directly target the detoxification process to eliminate HNE or directly prevent its formation. Nrf2: nuclear factor (erythroid-derived 2)-like 2 
To go further down this road: under physiological conditions, linked to oxidative stress, HNE levels have been shown to positively correlate with aging, and may be responsible for various aging-related diseases (cancer, NDD, macular degenerescence and atherosclerosis) through DNA and protein damage. Therefore, HNE is a key target for the chemoprevention of these pathologies. Several strategies are possible: decreasing the exposure to pro-oxidant inducers, quenching the HNE-generating ROS or increasing the detoxification capacity of the cells. The overexpression of SOD (superoxide dismutase) or catalase, the use of natural antioxidants (vitamin $\mathrm{C}$, vitamin $\mathrm{E}$ and $\beta$-carotene) or an increase in GSH synthesis have positive impacts on cellular protection. The improvement of cellular defenses is a relevant topic, with the use of natural compounds such as curcumin, sulforaphane, resveratrol or with chemical compounds such as $\mathrm{tBHQ}$ (tert-butylhydroquinone). They notably target the Nrf2 pathway.

To extend lifespan, a decrease in oxidative stress is recommended, by improving ROS and LPO sensing and maximizing the cellular antioxidant defenses. ${ }^{159}$ High-calorie diets (high fat and high carbohydrates) are linked to a high oxidant status in the organism, and recommended calorie restriction involves a decrease in total caloric intake while maintaining adequate nutrition, to extend the lifespan or improve health. Some enzymes, like HSP70, HO-1 or TRX1, involved in HNE detoxification belong to the vitagenes, a group of genes involved in the adaptation to oxidative stress and allow a greater resistance to long-lived animals. ${ }^{159}$ They are also regulated by Nrf2, which appears as a key protein in longevity. ${ }^{160}$ However, a chronic low level of HNE appears to be positive for longevity by continuously stimulating Nrf2 and antioxidant defense. ${ }^{72}$ Therefore, the links between HNE, detoxification pathways and diseases constitute a vast area of research for the understanding and the prevention of the major diseases of public health.

\section{Conflict of Interest}

The authors declare no conflict of interest.

Acknowledgements. We thank Dr. Cecile Héliés-Toussaint, Dr. Dominique Lagadic-Gossmann, Dr. Anthony Lemarié, Dr. Fabrice Pierre, Dr. Sylviane Tâché and John Woodley for critical reading and English corrections of the manuscript. Research in authors' laboratory is supported by grants from the Agence Nationale pour la Recherche (ANR SecuriViande); Ligue Régionale Midi-Pyrénées (contre le Cancer) and Institut National du Cancer (INCA NeoMeaTox).

1. Schaur RJ. Basic aspects of the biochemical reactivity of 4-hydroxynonenal. Mol Aspects Med 2003; 24: 149-159.

2. Duryee MJ, Willis MS, Freeman TL, Kuszynski CA, Tuma DJ, Klassen LW et al. Mechanisms of alcohol liver damage: aldehydes, scavenger receptors, and autoimmunity. Front Bio sci 2004; 9: 3145-3155.

3. Poli G, Schaur RJ, Siems WG, Leonarduzzi G. 4-hydroxynonenal: a membrane lipid oxidation product of medicinal interest. Med Res Rev 2008; 28: 569-631.

4. Uchida K, Toyokuni S, Nishikawa K, Kawakishi S, Oda H, Hiai $\mathrm{H}$ et al. Michael addition-type 4-hydroxy-2-nonenal adducts in modified low-density lipoproteins: markers for atherosclerosis. Biochemistry 1994; 33: 12487-12494.

5. Pierre F, Peiro G, Tache S, Cross AJ, Bingham SA, Gasc N et al. New marker of colon cancer risk associated with heme intake: 1,4-dihydroxynonane mercapturic acid. Cancer Epidemiol Biomarkers Prev 2006; 15: 2274-2279.

6. Wang X, Yang Y, Moore DR, Nimmo SL, Lightfoot SA, Huycke MM. 4-hydroxy-2-nonenal mediates genotoxicity and bystander effects caused by Enterococcus faecalis-infected macrophages. Gastroenterology 2012; 142: 543-551 e7.
7. Esterbauer H, Schaur RJ, Zollner H. Chemistry and biochemistry of 4-hydroxynonenal, malonaldehyde and related aldehydes. Free Radic Biol Med 1991; 11: 81-128.

8. Parola M, Bellomo G, Robino G, Barrera G, Dianzani MU. 4-Hydroxynonenal as a biological signal: molecular basis and pathophysiological implications. Antioxid Redox Signal 1999; 1: 255-284

9. Dwivedi S, Sharma A, Patrick B, Sharma R, Awasthi YC. Role of 4-hydroxynonenal and its metabolites in signaling. Redox Rep 2007; 12: 4-10.

10. Smathers RL, Fritz KS, Galligan JJ, Shearn CT, Reigan P, Marks MJ et al. Characterization of 4-HNE modified L-FABP reveals alterations in structural and functional dynamics. PLoS One 2012; 7: e38459.

11. Grune T, Michel P, Sitte N, Eggert W, Albrecht-Nebe H, Esterbauer $\mathrm{H}$ et al. Increased levels of 4-hydroxynonenal modified proteins in plasma of children with autoimmune diseases. Free Radic Biol Med 1997; 23: 357-360.

12. Siems WG, Brenke R, Beier A, Grune $T$. Oxidative stress in chronic lymphoedema. QJM 2002; 95: 803-809.

13. Siems W, Grune T. Intracellular metabolism of 4-hydroxynonenal. Mol Aspects Med 2003; 24: $167-175$

14. Baradat M, Jouanin I, Dalleau S, Tache S, Gieules M, Debrauwer L et al. 4-Hydroxy-2(E)nonenal metabolism differs in $\mathrm{Apc}(+/+)$ cells and in $\mathrm{Apc}(\mathrm{Min} /+)$ cells: it may explain colon cancer promotion by heme iron. Chem Res Toxicol 2011; 24: 1984-1993.

15. Siems WG, Zollner H, Grune T, Esterbauer H. Metabolic fate of 4-hydroxynonenal in hepatocytes: 1,4-dihydroxynonene is not the main product. J Lipid Res 1997; 38: 612-622.

16. Chiarpotto E, Domenicotti C, Paola D, Vitali A, Nitti M, Pronzato MA et al. Regulation of rat hepatocyte protein kinase $\mathrm{C}$ beta isoenzymes by the lipid peroxidation product 4-hydroxy2,3-nonenal: A signaling pathway to modulate vesicular transport of glycoproteins. Hepatology 1999; 29: 1565-1572.

17. Zhang $\mathrm{H}$, Forman HJ. Signaling pathways involved in phase II gene induction by alpha, beta-unsaturated aldehydes. Toxicol Ind Health 2009; 25: 269-278.

18. Pettazzoni P, Ciamporcero E, Medana C, Pizzimenti S, Dal Bello F, Minero VG et al. Nuclear factor erythroid 2-related factor-2 activity controls 4-hydroxynonenal metabolism and activity in prostate cancer cells. Free Radic Biol Med 2011; 51: 1610-1618.

19. Patrick B, Li J, Jeyabal PV, Reddy PM, Yang Y, Sharma R et al. Depletion of 4-hydroxynonenal in hGSTA4-transfected HLE B-3 cells results in profound changes in gene expression. Biochem Biophys Res Commun 2005; 334: 425-432.

20. Grune T, Davies KJ. The proteasomal system and HNE-modified proteins. Mol Aspects Med 2003; 24: 195-204.

21. Zarkovic K. 4-hydroxynonenal and neurodegenerative diseases. Mol Aspects Med 2003; 24: $293-303$

22. Choudhary S, Xiao T, Srivastava S, Zhang W, Chan LL, Vergara LA et al. Toxicity and detoxification of lipid-derived aldehydes in cultured retinal pigmented epithelial cells. Toxicol Appl Pharmacol 2005; 204: 122-134

23. Negre-Salvayre A, Vieira O, Escargueil-Blanc I, Salvayre R. Oxidized LDL and 4-hydroxynonenal modulate tyrosine kinase receptor activity. Mol Aspects Med 2003; 24: 251-261

24. Mattson MP. Roles of the lipid peroxidation product 4-hydroxynonenal in obesity, the metabolic syndrome, and associated vascular and neurodegenerative disorders. Exp Gerontol 2009; 44: 625-633

25. Karihtala P, Kauppila S, Puistola U, Jukkola-Vuorinen A. Divergent behaviour of oxidative stress markers 8-hydroxydeoxyguanosine (8-OHdG) and 4-hydroxy-2-nonenal (HNE) in breast carcinogenesis. Histopathology 2011; 58: 854-862.

26. Perry EA, Castellani RJ, Moreira PI, Nunomura A, Lui Q, Harris PL et al. Neurofilaments are the major neuronal target of hydroxynonenal-mediated protein cross-links. Free Radic Res 2013; 47: 507-510.

27. Butterfield DA, Swomley AM, Sultana R. Amyloid beta-peptide (1-42)-induced oxidative stress in alzheimer disease: importance in disease pathogenesis and progression. Antioxid Redox Signal 2013; 19: 823-835.

28. Shringarpure R, Grune T, Sitte N, Davies KJ. 4-Hydroxynonenal-modified amyloid-beta peptide inhibits the proteasome: possible importance in Alzheimer's disease. Cell Mol Life Sci 2000; 57: 1802-1809.

29. Rockwell P, Yuan H, Magnusson R, Figueiredo-Pereira ME. Proteasome inhibition in neuronal cells induces a proinflammatory response manifested by upregulation of cyclooxygenase-2, its accumulation as ubiquitin conjugates, and production of the prostaglandin PGE(2). Arch Biochem Biophys 2000; 374: 325-333

30. Keller JN, Pang Z, Geddes JW, Begley JG, Germeyer A, Waeg G et al. Impairment of glucose and glutamate transport and induction of mitochondrial oxidative stress and dysfunction in synaptosomes by amyloid beta-peptide: role of the lipid peroxidation product 4-hydroxynonenal. J Neurochem 1997; 69: 273-284.

31. Mark RJ, Lovell MA, Markesbery WR, Uchida K, Mattson MP. A role for 4-hydroxynonenal, an aldehydic product of lipid peroxidation, in disruption of ion homeostasis and neuronal death induced by amyloid beta-peptide. J Neurochem 1997; 68: 255-264

32. Jenner P. Oxidative stress in Parkinson's disease. Ann Neurol 2003; 53(Suppl 3): S26-S36; discussion S36-8.

33. Morel P, Tallineau C, Pontcharraud R, Piriou A, Huguet F. Effects of 4-hydroxynonenal, a lipid peroxidation product, on dopamine transport and $\mathrm{Na}+/ \mathrm{K}+$ ATPase in rat striatal synaptosomes. Neurochem Int 1998; 33: 531-540. 
34. Westerlund M, Galter D, Carmine A, Olson L. Tissue- and species-specific expression patterns of class I, III, and IV Adh and Aldh 1 mRNAs in rodent embryos. Cell Tissue Res 2005; 322: 227-236

35. Al Nimer F, Strom M, Lindblom R, Aeinehband S, Bellander BM, Nyengaard JR et al. Naturally occurring variation in the glutathione-s-transferase 4 gene determines neurodegeneration after traumatic brain injury. Antioxid Redox Signal 2013; 18: 784-794.

36. Hipkiss AR. Carnosine and its possible roles in nutrition and health. Adv Food Nutr Res 2009; $57: 87-154$

37. Hegyi L, Skepper JN, Cary NR, Mitchinson MJ. Foam cell apoptosis and the development of the lipid core of human atherosclerosis. J Pathol 1996; 180: 423-429.

38. Vindis C, Escargueil-Blanc I, Elbaz M, Marcheix B, Grazide MH, Uchida K et al. Desensitization of platelet-derived growth factor receptor-beta by oxidized lipids in vascular cells and atherosclerotic lesions: prevention by aldehyde scavengers. Circ Res 2006; 98: 785-792.

39. Leonarduzzi G, Chiarpotto E, Biasi F, Poli G. 4-Hydroxynonenal and cholesterol oxidation products in atherosclerosis. Mol Nutr Food Res 2005; 49: 1044-1049.

40. Herbst U, Toborek M, Kaiser S, Mattson MP, Hennig B. 4-Hydroxynonenal induces dysfunction and apoptosis of cultured endothelial cells. J Cell Physiol 1999; 181: 295-303.

41. Hajjar DP, Haberland ME. Lipoprotein trafficking in vascular cells. Molecular Trojan horses and cellular saboteurs. J Biol Chem 1997; 272: 22975-22978.

42. VanWinkle WB, Snuggs M, Miller JC, Buja LM. Cytoskeletal alterations in cultured cardiomyocytes following exposure to the lipid peroxidation product, 4-hydroxynonenal. Cell Motil Cytoskeleton 1994; 28: 119-134.

43. Singh R, Wang Y, Schattenberg JM, Xiang Y, Czaja MJ. Chronic oxidative stress sensitizes hepatocytes to death from 4-hydroxynonenal by JNK/c-Jun overactivation. Am J Physiol Gastrointest Liver Physiol 2009; 297: G907-G917.

44. Mottaran E, Stewart SF, Rolla R, Vay D, Cipriani V, Moretti M et al. Lipid peroxidation contributes to immune reactions associated with alcoholic liver disease. Free Radic Biol Med 2002; 32: 38-45.

45. Dou X, Li S, Wang Z, Gu D, Shen C, Yao T et al. Inhibition of NF-kappaB activation by 4-hydroxynonenal contributes to liver injury in a mouse model of alcoholic liver disease. Am J Pathol 2012; 181: 1702-1710.

46. Valentovic M, Terneus M, Harmon RC, Carpenter AB. S-Adenosylmethionine (SAMe) attenuates acetaminophen hepatotoxicity in C57BL/6 mice. Toxicol Lett 2004; 154 165-174.

47. Barrera G. Oxidative stress and lipid peroxidation products in cancer progression and therapy. ISRN Oncol 2012; 2012: 137289.

48. Cheeseman KH, Burton GW, Ingold KU, Slater TF. Lipid peroxidation and lipid antioxidants in normal and tumor cells. Toxicol Pathol 1984; 12: 235-239.

49. Tjalkens RB, Cook LW, Petersen DR. Formation and export of the glutathione conjugate of 4-hydroxy-2, 3-E-nonenal (4-HNE) in hepatoma cells. Arch Biochem Biophys 1999; 361: 113-119.

50. Oberley TD, Toyokuni S, Szweda LI. Localization of hydroxynonenal protein adducts in normal human kidney and selected human kidney cancers. Free Radic Biol Med 1999; 27: 695-703.

51. Biasi F, Tessitore L, Zanetti D, Cutrin JC, Zingaro B, Chiarpotto E et al. Associated changes of lipid peroxidation and transforming growth factor beta1 levels in human colon cancer during tumour progression. Gut 2002; 50: 361-367.

52. Skrzydlewska E, Stankiewicz A, Sulkowska M, Sulkowski S, Kasacka I. Antioxidant status and lipid peroxidation in colorectal cancer. J Toxicol Environ Health A 2001; 64 213-222.

53. Young O, Crotty T, O'Connell R, O'Sullivan J, Curran AJ. Levels of oxidative damage and lipid peroxidation in thyroid neoplasia. Head Neck 2010; 32: 750-756.

54. Juric-Sekhar G, Zarkovic K, Waeg G, Cipak A, Zarkovic N. Distribution of 4-hydroxynonenal-protein conjugates as a marker of lipid peroxidation and parameter of malignancy in astrocytic and ependymal tumors of the brain. Tumori 2009; 95: 762-768.

55. Marquez-Quinones A, Cipak A, Zarkovic K, Fattel-Fazenda S, Villa-Trevino S, Waeg G et al. HNE-protein adducts formation in different pre-carcinogenic stages of hepatitis in LEC rats. Free Radic Res 2010; 44: 119-127.

56. Dianzani MU. Lipid peroxidation and cancer: a critical reconsideration. Tumori 1989; 75 351-357.

57. DeNicola GM, Karreth FA, Humpton TJ, Gopinathan A, Wei C, Frese K et al. Oncogeneinduced Nrf2 transcription promotes ROS detoxification and tumorigenesis. Nature 2011; 475: 106-109.

58. Dianzani MU. Lipid peroxidation and cancer. Crit Rev Oncol Hematol 1993; 15: 125-147.

59. Pierre F, Tache S, Gueraud F, Rerole AL, Jourdan ML, Petit C. Apc mutation induces resistance of colonic cells to lipoperoxide-triggered apoptosis induced by faecal water from haem-fed rats. Carcinogenesis 2007; 28: 321-327.

60. Feng Z, Hu W, Amin S, Tang MS. Mutational spectrum and genotoxicity of the major lipid peroxidation product, trans-4-hydroxy-2-nonenal, induced DNA adducts in nucleotide excision repair-proficient and -deficient human cells. Biochemistry 2003; 42: 7848-7854.

61. Hu W, Feng Z, Eveleigh J, lyer G, Pan J, Amin S et al. The major lipid peroxidation product, trans-4-hydroxy-2-nonenal, preferentially forms DNA adducts at codon 249 of human p53 gene, a unique mutational hotspot in hepatocellular carcinoma. Carcinogenesis 2002; 23: 1781-1789.
62. Feng Z, Hu W, Tang MS. Trans-4-hydroxy-2-nonenal inhibits nucleotide excision repair in human cells: a possible mechanism for lipid peroxidation-induced carcinogenesis. Proc Natl Acad Sci USA 2004; 101: 8598-8602.

63. Cheng JZ, Sharma R, Yang Y, Singhal SS, Sharma A, Saini MK et al. Accelerated metabolism and exclusion of 4-hydroxynonenal through induction of RLIP76 and hGST5.8 is an early adaptive response of cells to heat and oxidative stress. J Biol Chem 2001; 276: 41213-41223

64. Yang Y, Sharma A, Sharma R, Patrick B, Singhal SS, Zimniak $P$ et al. Cells preconditioned with mild, transient UVA irradiation acquire resistance to oxidative stress and UVA-induced apoptosis: role of 4-hydroxynonenal in UVA-mediated signaling for apoptosis. J Biol Chem 2003; 278: 41380-41388.

65. Ramachandran V, Watts LT, Maffi SK, Chen J, Schenker S, Henderson G. Ethanolinduced oxidative stress precedes mitochondrially mediated apoptotic death of cultured fetal cortical neurons. J Neurosci Res 2003; 74: 577-588.

66. Wallach D, Kang TB, Kovalenko A. The extrinsic cell death pathway and the elan mortel. Cell Death Differ 2008; 15: 1533-1541.

67. Li J, Sharma R, Patrick B, Sharma A, Jeyabal PV, Reddy PM et al. Regulation of CD95 (Fas) expression and Fas-mediated apoptotic signaling in HLE B-3 cells by 4hydroxynonenal. Biochemistry 2006; 45: 12253-12264.

68. Engle MR, Singh SP, Czernik PJ, Gaddy D, Montague DC, Ceci JD et al. Physiological role of mGSTA4-4, a glutathione S-transferase metabolizing 4-hydroxynonenal: generation and analysis of mGsta4 null mouse. Toxicol Appl Pharmacol 2004; 194: 296-308.

69. Sharma R, Sharma A, Dwivedi S, Zimniak P, Awasthi S, Awasthi YC. 4-Hydroxynonenal self-limits fas-mediated DISC-independent apoptosis by promoting export of Daxx from the nucleus to the cytosol and its binding to Fas. Biochemistry 2008; 47: 143-156.

70. Salomoni P, Khelifi AF. Daxx: death or survival protein? Trends Cell Biol 2006; 16 97-104.

71. Yang X, Khosravi-Far R, Chang HY, Baltimore D. Daxx a novel Fas-binding protein that activates JNK and apoptosis. Cell 1997; 89: 1067-1076.

72. Singh SP, Niemczyk M, Saini D, Sadovov V, Zimniak L, Zimniak P. Disruption of the mGsta4 gene increases life span of C57BL mice. J Gerontol A Biol Sci Med Sci 2010; 65 $14-23$.

73. Torii S, Egan DA, Evans RA, Reed JC. Human Daxx regulates Fas-induced apoptosis from nuclear PML oncogenic domains (PODs). EMBO J 1999; 18: 6037-6049.

74. West JD, Marnett LJ. Alterations in gene expression induced by the lipid peroxidation product, 4-hydroxy-2-nonenal. Chem Res Toxicol 2005; 18: 1642-1653.

75. Weigel AL, Handa JT, Hjelmeland LM. Microarray analysis of H2O2-, HNE-, or tBH-treated ARPE-19 cells. Free Radic Biol Med 2002; 33: 1419-1432.

76. Marchette LD, Wang H, Li F, Babizhayev MA, Kasus-Jacobi A. Carcinine has 4-hydroxynonenal scavenging property and neuroprotective effect in mouse retina. Inves Ophthalmol Vis Sci 53: 3572-3583.

77. Battisti V, Maders LD, Bagatini MD, Santos KF, Spanevello RM, Maldonado PA et al. Measurement of oxidative stress and antioxidant status in acute lymphoblastic leukemia patients. Clin Biochem 2008; 41: 511-518.

78. Khanna S, Sen CK, Roy S, Christen MO, Packer L. Protective effects of anethole dithiolethione against oxidative stress-induced cytotoxicity in human Jurkat $\mathrm{T}$ cells. Biochem Pharmacol 1998; 56: 61-69.

79. Galluzzi L, Joza N, Tasdemir E, Maiuri MC, Hengartner M, Abrams JM et al. No death without life: vital functions of apoptotic effectors. Cell Death Differ 2008; 15: 1113-1123.

80. Haynes RL, Brune B, Townsend AJ. Apoptosis in RAW 264.7 cells exposed to 4-hydroxy2-nonenal: dependence on cytochrome $\mathrm{C}$ release but not p53 accumulation. Free Radic Biol Med 2001; 30: 884-894

81. Braga M, Sinha Hikim AP, Datta S, Ferrini MG, Brown D, Kovacheva EL et al. Involvement of oxidative stress and caspase 2-mediated intrinsic pathway signaling in age-related increase in muscle cell apoptosis in mice. Apoptosis 2008; 13: 822-832.

82. Ji C, Amarnath V, Pietenpol JA, Marnett LJ. 4-hydroxynonenal induces apoptosis via caspase-3 activation and cytochrome c release. Chem Res Toxicol 2001; 14 1090-1096.

83. Siddiqui MA, Kumar V, Kashyap MP, Agarwal M, Singh AK, Khanna VK et al. Short-term exposure of 4-hydroxynonenal induces mitochondria-mediated apoptosis in PC12 cells. Hum Exp Toxicol 2012; 31: 336-345.

84. Hill BG, Dranka BP, Zou L, Chatham JC, Darley-Usmar VM. Importance of the bioenergetic reserve capacity in response to cardiomyocyte stress induced by 4-hydroxynonenal. Biochem J 2009; 424: 99-107.

85. Bodur C, Kutuk O, Tezil T, Basaga H. Inactivation of Bcl-2 through lkappaB kinase (IKK)dependent phosphorylation mediates apoptosis upon exposure to 4-hydroxynonena (HNE). J Cell Physiol 2012; 227: 3556-3565.

86. Liu W, Porter NA, Schneider C, Brash AR, Yin H. Formation of 4-hydroxynonenal from cardiolipin oxidation: Intramolecular peroxyl radical addition and decomposition. Free Radic Biol Med 2011; 50: 166-178.

87. Raza H, John A. 4-hydroxynonenal induces mitochondrial oxidative stress, apoptosis and expression of glutathione S-transferase A4-4 and cytochrome P450 2E1 in PC12 cells. Toxicol Appl Pharmacol 2006; 216: 309-318.

88. Liu W, Kato M, Akhand AA, Hayakawa A, Suzuki H, Miyata T et al. 4-hydroxynonenal induces a cellular redox status-related activation of the caspase cascade for apoptotic cell death. J Cell Sci 2000; 113(Pt 4): 635-641. 
89. Lee JY, Jung GY, Heo HJ, Yun MR, Park JY, Bae SS et al. 4-Hydroxynonenal induces vascular smooth muscle cell apoptosis through mitochondrial generation of reactive oxygen species. Toxicol Lett 2006; 166: 212-221.

90. Uchida K, Shiraishi M, Naito Y, Torii Y, Nakamura Y, Osawa T. Activation of stress signaling pathways by the end product of lipid peroxidation. 4-hydroxy-2-nonenal is a potential inducer of intracellular peroxide production. J Biol Chem 1999; 274: 2234-2242.

91. Dhanasekaran DN, Reddy EP. JNK signaling in apoptosis. Oncogene 2008; 27: 6245-6251.

92. Parola M, Robino G, Marra F, Pinzani M, Bellomo G, Leonarduzzi G et al. HNE interacts directly with JNK isoforms in human hepatic stellate cells. J Clin Invest 1998; 102 1942-1950.

93. Song BJ, Soh Y, Bae M, Pie J, Wan J, Jeong K. Apoptosis of PC12 cells by 4-hydroxy-2nonenal is mediated through selective activation of the c-Jun $\mathrm{N}$-terminal protein kinase pathway. Chem Biol Interact 2001; 130-132: 943-954.

94. Kutuk O, Basaga H. Apoptosis signalling by 4-hydroxynonenal: a role for JNK-c-Jun/AP-1 pathway. Redox Rep 2007; 12: 30-34

95. Bruckner SR, Estus S. JNK3 contributes to c-jun induction and apoptosis in 4-hydroxynonenal-treated sympathetic neurons. J Neurosci Res 2002; 70: 665-670.

96. Kutuk O, Poli G, Basaga $\mathrm{H}$. Resveratrol protects against 4-hydroxynonenal-induced apoptosis by blocking JNK and c-JUN/AP-1 signaling. Toxicol Sci 2006; 90: 120-132.

97. Jang YJ, Kim JE, Kang NJ, Lee KW, Lee HJ. Piceatannol attenuates 4-hydroxynonenalinduced apoptosis of PC12 cells by blocking activation of c-Jun N-terminal kinase. Ann N Y Acad Sci 2009; 1171: 176-182.

98. Sharma A, Sharma R, Chaudhary P, Vatsyayan R, Pearce V, Jeyabal PV et al 4-Hydroxynonenal induces p53-mediated apoptosis in retinal pigment epithelial cells. Arch Biochem Biophys 2008; 480: 85-94.

99. Knoll N, Ruhe C, Veeriah S, Sauer J, Glei M, Gallagher EP et al. Genotoxicity of 4-hydroxy-2-nonenal in human colon tumor cells is associated with cellular levels of glutathione and the modulation of glutathione S-transferase A4 expression by butyrate. Toxicol Sci 2005; 86: 27-35.

100. Eckl PM. Genotoxicity of HNE. Mol Aspects Med 2003; 24: 161-165.

101. Buizza L, Prandelli C, Bonini SA, Delbarba A, Cenini G, Lanni C et al. Conformational altered p53 affects neuronal function: relevance for the response to toxic insult and growth-associated protein 43 expression. Cell Death Dis 2013; 4: e484.

102. Barone E, Cenini G, Sultana R, Di Domenico F, Fiorini A, Perluigi M et al. Lack of p53 decreases basal oxidative stress levels in the brain through upregulation of thioredoxin-1, biliverdin reductase-A, manganese superoxide dismutase, and nuclear factor kappa-B. Antioxid Redox Signal 2012; 16: 1407-1420.

103. Cenini G, Sultana R, Memo M, Butterfield DA. Elevated levels of pro-apoptotic p53 and its oxidative modification by the lipid peroxidation product, $\mathrm{HNE}$, in brain from subjects with amnestic mild cognitive impairment and Alzheimer's disease. J Cell Mol Med 2008; 12 987-994.

104. Choudhary S, Zhang W, Zhou F, Campbell GA, Chan LL, Thompson EB et al. Cellular lipid peroxidation end-products induce apoptosis in human lens epithelial cells. Free Radic Biol Med 2002; 32: 360-369.

105. Kruman II, Mattson MP. Pivotal role of mitochondrial calcium uptake in neural cell apoptosis and necrosis. J Neurochem 1999; 72: 529-540.

106. Peng ZF, Koh CH, Li QT, Manikandan J, Melendez AJ, Tang SY et al. Deciphering the mechanism of HNE-induced apoptosis in cultured murine cortical neurons: transcriptional responses and cellular pathways. Neuropharmacology 2007; 53: 687-698.

107. Chaudhary P, Sharma R, Sharma A, Vatsyayan R, Yadav S, Singhal SS et al Mechanisms of 4-hydroxy-2-nonenal induced pro- and anti-apoptotic signaling Biochemistry 2010; 49: 6263-6275.

108. Ferrington DA, Kapphahn RJ. Catalytic site-specific inhibition of the $20 \mathrm{~S}$ proteasome by 4-hydroxynonenal. FEBS Lett 2004; 578: 217-223.

109. Vladykovskaya E, Sithu SD, Haberzettl P, Wickramasinghe NS, Merchant ML Hill BG et al. Lipid peroxidation product 4-hydroxy-trans-2-nonenal causes endothelial activation by inducing endoplasmic reticulum stress. J Biol Chem 2012 287: 11398-11409

110. Muller C, Bandemer J, Vindis C, Camare C, Mucher E, Gueraud F et al. Protein disulfide isomerase modification and inhibition contribute to er stress and apoptosis induced by oxidized low density lipoproteins. Antioxid Redox Signal 2013; 18: 731-742.

111. Santos CX. Tanaka LY, Wosniak J, Laurindo FR. Mechanisms and implications of reactive oxygen species generation during the unfolded protein response: roles of endoplasmic reticulum oxidoreductases, mitochondrial electron transport, and NADPH oxidase. Antioxid Redox Signal 2009; 11: 2409-2427.

112. Sovic A, Borovic S, Loncaric I, Kreuzer T, Zarkovic K, Vukovic T et al. The carcinostatic and proapoptotic potential of 4-hydroxynonenal in HeLa cells is associated with its conjugation to cellular proteins. Anticancer Res 2001; 21: 1997-2004.

113. Bresgen N, Jaksch $\mathrm{H}$, Lacher H, Ohlenschlager I, Uchida K, Eckl PM. Iron mediated oxidative stress plays an essential role in ferritin induced cell death. Free Radic Biol Med 2010; 48: 1347-1357

114. Dixon SJ, Lemberg KM, Lamprecht MR, Skouta R, Zaitsev EM, Gleason CE et al. Ferroptosis: an iron-dependent form of nonapoptotic cell death. Cell 2012; 149 . 1060-1072

115. Green DR, Victor B. The pantheon of the fallen: why are there so many forms of cell death? Trends Cell Biol 2012; 22: 555-556.
116. Jacobs AT, Marnett LJ. Heat shock factor 1 attenuates 4-hydroxynonenal-mediated apoptosis: critical role for heat shock protein 70 induction and stabilization of $\mathrm{Bcl}-\mathrm{XL}$. J Biol Chem 2007; 282: 33412-33420.

117. Jacobs AT, Marnett LJ. HSF1-mediated BAG3 expression attenuates apoptosis in 4-hydroxynonenal-treated colon cancer cells via stabilization of anti-apoptotic Bcl-2 proteins. J Biol Chem 2009; 284: 9176-9183.

118. Vermeulen K, Van Bockstaele DR, Berneman ZN. The cell cycle: a review of regulation, deregulation and therapeutic targets in cancer. Cell Prolif 2003; 36: 131-149.

119. Barrera G, Pizzimenti S, Laurora S, Briatore F, Toaldo C, Dianzani MU. 4-hydroxynonenal and cell cycle. Biofactors 2005; 24: 151-157.

120. Pizzimenti S, Barrera G, Dianzani MU, Brusselbach S. Inhibition of D1, D2, and A-cyclin expression in $\mathrm{HL}-60$ cells by the lipid peroxydation product 4-hydroxynonenal. Free Radic Biol Med 1999; 26: 1578-1586.

121. Wonisch W, Kohlwein SD, Schaur J, Tatzber F, Guttenberger H, Zarkovic N et al. Treatment of the budding yeast Saccharomyces cerevisiae with the lipid peroxidation product 4-HNE provokes a temporary cell cycle arrest in G1 phase. Free Radic Biol Med 1998; 25: 682-687.

122. Pettazzoni $\mathrm{P}$, Pizzimenti S, Toaldo $\mathrm{C}$, Sotomayor $\mathrm{P}$, Tagliavacca L, Liu S et al. Induction of cell cycle arrest and DNA damage by the HDAC inhibitor panobinostat (LBH589) and the lipid peroxidation end product 4-hydroxynonenal in prostate cancer cells. Free Radic Biol Med 50: 313-322.

123. Laurora S, Tamagno E, Briatore F, Bardini P, Pizzimenti S, Toaldo C et al. 4-Hydroxynonenal modulation of p53 family gene expression in the SK-N-BE neuroblastoma cell line. Free Radic Biol Med 2005; 38: 215-225.

124. Ahmed EK, Rogowska-Wrzesinska A, Roepstorf $P$, Bulteau AL, Friguet B. Protein modification and replicative senescence of WI-38 human embryonic fibroblasts. Aging Cell 2010; 9: 252-272.

125. Voghel G, Thorin-Trescases N, Farhat N, Mamarbachi AM, Villeneuve L, Fortier A et al. Chronic treatment with $\mathrm{N}$-acetyl-cystein delays cellular senescence in endothelial cells isolated from a subgroup of atherosclerotic patients. Mech Ageing Dev 2008; 129 : 261-270.

126. Kim NW, Piatyszek MA, Prowse KR, Harley CB, West MD, Ho PL et al. Specific association of human telomerase activity with immortal cells and cancer. Science 1994; 266: 2011-2015.

127. von Zglinicki T. Oxidative stress shortens telomeres. Trends Biochem Sci 2002; 27 339-344.

128. Pizzimenti S, Menegatti E, Berardi D, Toaldo C, Pettazzoni P, Minelli R et al. 4-hydroxynonenal, a lipid peroxidation product of dietary polyunsaturated fatty acids, has anticarcinogenic properties in colon carcinoma cell lines through the inhibition of telomerase activity. J Nutr Biochem 2010; 21: 818-826.

129. Neely MD, Zimmerman L, Picklo MJ, Ou JJ, Morales CR, Montine KS et al. Congeners of $\mathrm{N}$ (alpha)-acetyl-L-cysteine but not aminoguanidine act as neuroprotectants from the lipid peroxidation product 4-hydroxy-2-nonenal. Free Radic Biol Med 2000; 29: 1028-1036.

130. Riahi Y, Kaiser N, Leibowitz G, Sima AV, Simionescu M, Sasson S. Mechanism of foam cell-induced endothelial cell senescence in atherosclerosis. EAS Congress Abstract book 80th European Atherosclerosis Society Congress, 2012, p 831.

131. Hill BG, Haberzettl $P$, Ahmed $Y$, Srivastava $S$, Bhatnagar A. Unsaturated lipid peroxidation-derived aldehydes activate autophagy in vascular smooth-muscle cells. Biochem J 2008; 410: 525-534.

132. Schutt F, Bergmann M, Holz FG, Kopitz J. Proteins modified by malondialdehyde, 4-hydroxynonenal, or advanced glycation end products in lipofuscin of human retinal pigment epithelium. Invest Ophthalmol Vis Sci 2003; 44: 3663-3668.

133. Krohne TU, Stratmann NK, Kopitz J, Holz FG. Effects of lipid peroxidation products on lipofuscinogenesis and autophagy in human retinal pigment epithelial cells. Exp Eye Res 2010; 90: 465-471.

134. Sparrow JR, Boulton M. RPE lipofuscin and its role in retinal pathobiology. Exp Eye Res 2005; 80: 595-606.

135. Salabei JK, Cummins TD, Singh M, Jones SP, Bhatnagar A, Hill BG. PDGF-mediated autophagy regulates vascular smooth muscle cell phenotype and resistance to oxidative stress. Biochem J 2013; 451: 375-388.

136. Wakabayashi N, Slocum SL, Skoko JJ, Shin S, Kensler TW. When NRF2 talks, who's listening? Antioxid Redox Signal 2010; 13: 1649-1663.

137. Dinkova-Kostova AT, Holtzclaw WD, Cole RN, Itoh K, Wakabayashi N, Katoh Y et al. Direct evidence that sulfhydryl groups of Keap1 are the sensors regulating induction of phase 2 enzymes that protect against carcinogens and oxidants. Proc Natl Acad Sci USA 2002: 99: 11908-11913.

138. Levonen AL, Landar A, Ramachandran A, Ceaser EK, Dickinson DA, Zanoni G et al. Cellular mechanisms of redox cell signalling: role of cysteine modification in controlling antioxidant defences in response to electrophilic lipid oxidation products. Biochem J2004; 378(Pt 2): 373-382.

139. Levy S, Jaiswal AK, Forman HJ. The role of c-Jun phosphorylation in EpRE activation of phase II genes. Free Radic Biol Med 2009; 47: 1172-1179.

140. Singh S, Vrishni S, Singh BK, Rahman I, Kakkar P. Nrf2-ARE stress response mechanism: a control point in oxidative stress-mediated dysfunctions and chronic inflammatory diseases. Free Radic Res 2010; 44: 1267-1288. 
141. Siow RC, Ishii T, Mann GE. Modulation of antioxidant gene expression by 4-hydroxynonenal: atheroprotective role of the Nrf2/ARE transcription pathway. Redox Rep 2007; 12: 11-15.

142. Sporn MB, Liby KT. NRF2 and cancer: the good, the bad and the importance of context. Nat Rev Cancer 2012; 12: 564-571.

143. Awasthi YC, Ansari GA, Awasthi S. Regulation of 4-hydroxynonenal mediated signaling by glutathione S-transferases. Methods Enzymol 2005; 401: 379-407.

144. Kong D, Kotraiah V. Modulation of aldehyde dehydrogenase activity affects $(+/ /$ )4-hydroxy-2E-nonenal (HNE) toxicity and HNE-protein adduct levels in PC12 cells. J Mol Neurosci 2012; 47: 595-603.

145. Murphy TC, Amarnath V, Gibson KM, Picklo MJ Sr. Oxidation of 4-hydroxy-2-nonenal by succinic semialdehyde dehydrogenase (ALDH5A). J Neurochem 2003; 86: 298-305.

146. Banaclocha MM. Therapeutic potential of $\mathrm{N}$-acetylcysteine in age-related mitochondrial neurodegenerative diseases. Med Hypotheses 2001; 56: 472-477.

147. Circu ML, Aw TY. Glutathione and apoptosis. Free Radic Res 2008; 42: 689-706.

148. Vaillancourt $F$, Fahmi $H$, Shi Q, Lavigne $P$, Ranger $P$, Fernandes JC et al. 4-Hydroxynonenal induces apoptosis in human osteoarthritic chondrocytes: the protective role of glutathione-S-transferase. Arthritis Res Ther 2008; 10: R107.

149. Gallagher EP, Huisden CM, Gardner JL. Transfection of HepG2 cells with hGSTA4 provides protection against 4-hydroxynonenal-mediated oxidative injury. Toxicol In Vitro 2007; 21: 1365-1372.

150. Li D, Hinshelwood A, Gardner R, McGarvie G, Ellis EM. Mouse aldo-keto reductase AKR7A5 protects V79 cells against 4-hydroxynonenal-induced apoptosis. Toxicology 2006; 226: 172-180.

151. Matsunaga T, Shinoda $Y$, Inoue $Y$, Endo S, El-Kabbani O, Hara A. Protective effect of rat aldo-keto reductase (AKR1C15) on endothelial cell damage elicited by 4-hydroxy-2nonenal. Chem Biol Interact 191: 364-370.
152. Solito R, Chen $\mathrm{CH}$, Mochly-Rosen D, Giachetti A, Ziche M, Donnini S. Mitochondrial aldehyde dehydrogenase-2 activation prevents beta amyloids induced endothelial cell dysfunction and restores angiogenesis. J Cell Sci 2013; 126(Pt 9): 1952-1961.

153. Pappa A, Chen C, Koutalos Y, Townsend AJ, Vasiliou V. Aldh3a1 protects human corneal epithelial cells from ultraviolet- and 4-hydroxy-2-nonenal-induced oxidative damage. Free Radic Biol Med 2003; 34: 1178-1189.

154. Mitsuishi Y, Taguchi K, Kawatani $\mathrm{Y}$, Shibata T, Nukiwa T, Aburatani $\mathrm{H}$ et al. Nrf2 redirects glucose and glutamine into anabolic pathways in metabolic reprogramming. Cancer Cell 2012; 22: 66-79.

155. Ruef J, Rao GN, Li F, Bode C, Patterson C, Bhatnagar A et al. Induction of rat aortic smooth muscle cell growth by the lipid peroxidation product 4-hydroxy-2-nonenal. Circulation 1998; 97: 1071-1078.

156. Barrera G, Di Mauro C, Muraca R, Ferrero D, Cavalli G, Fazio VM et al. Induction of differentiation in human $\mathrm{HL}-60$ cells by 4-hydroxynonenal, a product of lipid peroxidation. Exp Cell Res 1991; 197: 148-152.

157. Pizzimenti S, Laurora S, Briatore F, Ferretti C, Dianzani MU, Barrera G. Synergistic effect of 4-hydroxynonenal and PPAR ligands in controlling human leukemic cell growth and differentiation. Free Radic Biol Med 2002; 32: 233-245.

158. Zhang W, He Q, Chan LL, Zhou F, El Naghy M, Thompson EB et al. Involvement of caspases in 4-hydroxy-alkenal-induced apoptosis in human leukemic cells. Free Radic Biol Med 2001; 30: 699-706.

159. Calabrese V, Cornelius C, Mancuso C, Pennisi G, Calafato S, Bellia F et al. Cellular stress response: a novel target for chemoprevention and nutritional neuroprotection in aging, neurodegenerative disorders and longevity. Neurochem Res 2008; 33: 2444-2471.

160. Sykiotis GP, Bohmann D. Keap1/Nrf2 signaling regulates oxidative stress tolerance and lifespan in Drosophila. Dev Cell 2008; 14: 76-85. 